\title{
Review
}

\section{State of the Art of Automated Buses}

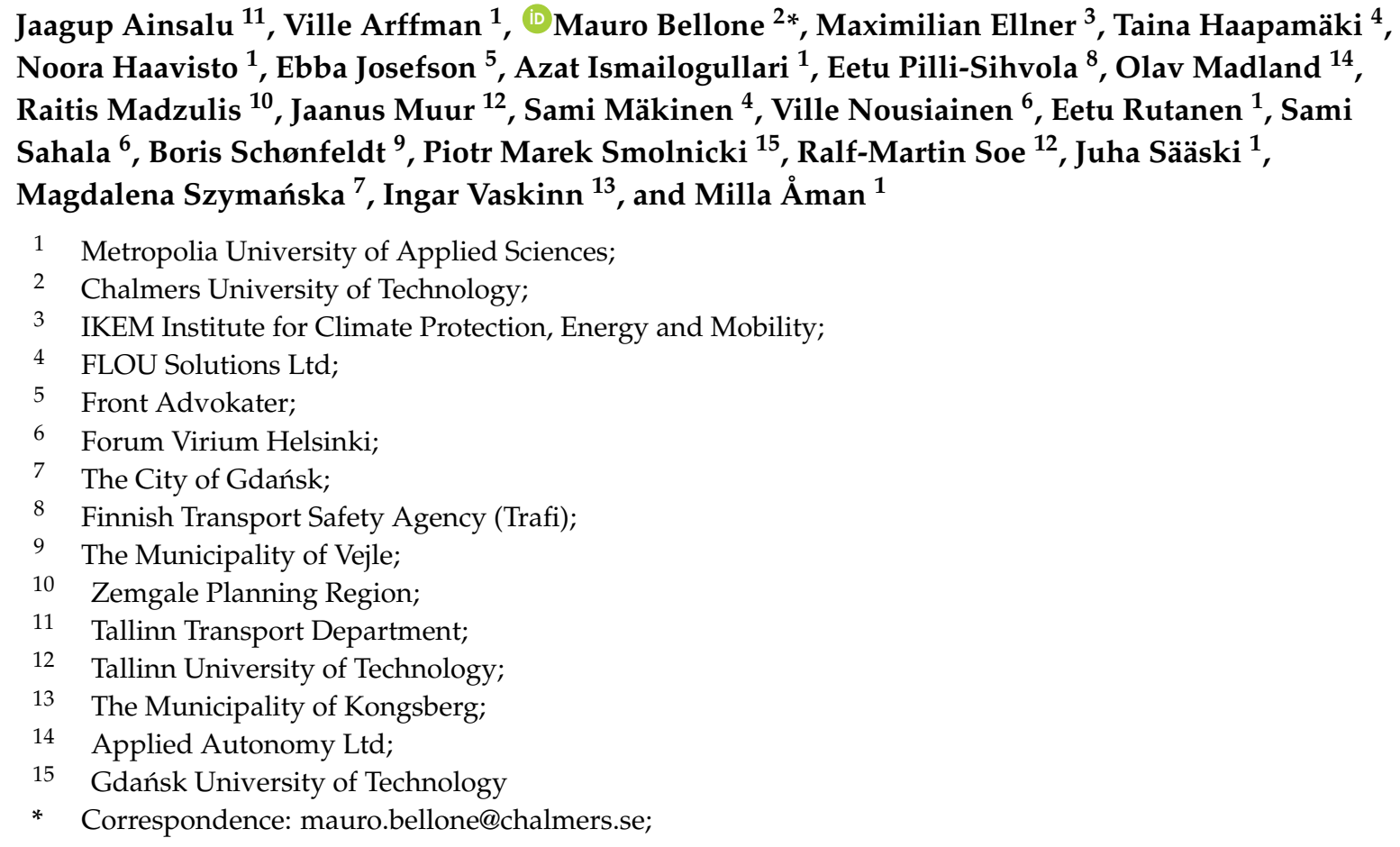

\begin{abstract}
Urban transportation in the next few decades will shift worldwide towards electrification and automation, with the final aim of increasing energy efficiency and safety for passengers. Such a big change requires strong collaboration and efforts among public administration, research and stakeholders in developing, testing and promoting these technologies in the public transportation. Working in this direction, this work provides a review of the impact of the introduction of driverless electric minibuses, for the first and last mile transportation, in the public service. More specifically, this paper covers a state of the art in terms of technological background for automation, energy efficiency via electrification, and the current state of the legal framework in Europe with focus on the Baltic Sea Region.
\end{abstract}

Keywords: Automated buses; Electrification; Intelligent Urban Transportation;

\section{Introduction}

Recent research and demos have demonstrated that driverless vehicles are able to drive safely in the majority of common road scenarios worldwide. This trend is encouraging further investments from industry and public administrations in order to make autonomous driving technologies available to everyone. However, more efforts are required to meet the demand for higher performance and safety; for example, in a recent report [? ] Google claimed that in 2015 their cars experienced 272 failures, and would have crashed at least 13 times if their human test drivers had not intervened, driving between 30.000 to 40.000 miles per month. Further failures are documented by all the other manufacturers working in this sector, including a casualty during an Uber test in Arizona in March 2018 [? ].

Public transportation can strongly benefit from the introduction of intelligent vehicles as they can improve safety in urban areas, reduce the cost for the last-mile transportation, decrease congestion, and improve the global service for the user. Although autonomous vehicle technology is not completely mature yet, it has been attracting economic and industrial interests for years, to such an extent that 
commercial cars include increasing levels of advanced driver assisting systems year after year. On the one hand, social implications of such a huge revolution will change our way of seeing the transportation systems, hence increasing the quality of our life. On the other hand, vehicles will have to be equipped with a large number of sensors that are still expensive and, most importantly, safety and reliability are mandatory, but still open requirements. Moreover, the impact of driverless vehicles on cities could result in both positive consequences and negative side effects [? ]. The automated mobility will be much safer and more accessible for those who cannot drive themselves or do not own a car, following the Mobility as a Service (MaaS) paradigm (no need of vehicle ownership). Under an upright policy the vehicle automation will support public transit as well as decrease housing development costs, especially due to the elimination of expensive underground garages and space-wasting on-ground parking. Therefore, there will be higher chances for building affordable urban housing. However, if regulations will be depraved, the ubiquitous automated mobility could lead to numerous side effects, i.e. the growth of traffic congestion, obesity, urban sprawl, or reduced mass public transit use.

Following these objectives, researchers and industries are working on improving more and more their global performance, and today fully-autonomous cars are just one step away from market and worldwide diffusion. In the event of their imminent market entry, many countries in the world are preparing their legislation for the road circulation of autonomous cars. Moreover, public authorities have to deal with the transition to new modes of transportation and shared mobility, improving regional planning and modelling, roads management and operations, automated vehicle human factors, near-term deployment opportunities, automation systems operational requirements and street infrastructure needs of connected-automated vehicles. Once autonomous buses become legally standardized and commercially available, they could serve many trips currently served by privately owned vehicles, but the majority of these issues are still not completely solved. And, as long as these and other crucial questions remain unanswered, the public administration will be hampered in its ability to successfully plan for and introduce automated buses into the transportation system.

The report first describes the motivation to implement automated vehicles into the public transport system (Section 2). Then, in Section 3, it shows that there are different models of automated mobility. In a further section, it gives an overview of ongoing and future automated mobility pilots (4.). After that, it goes into further detail discussing the technological background of automated driving, in Section 5, outlining the necessary specifications of the routes and vehicles involved in automated mobility pilots, reported in Section 6. The study is concluded by a section on the regulatory framework of automated mobility (7.) with a special focus on civil liability (Section 8) and important safety and standardization issues addressed in Section 9.

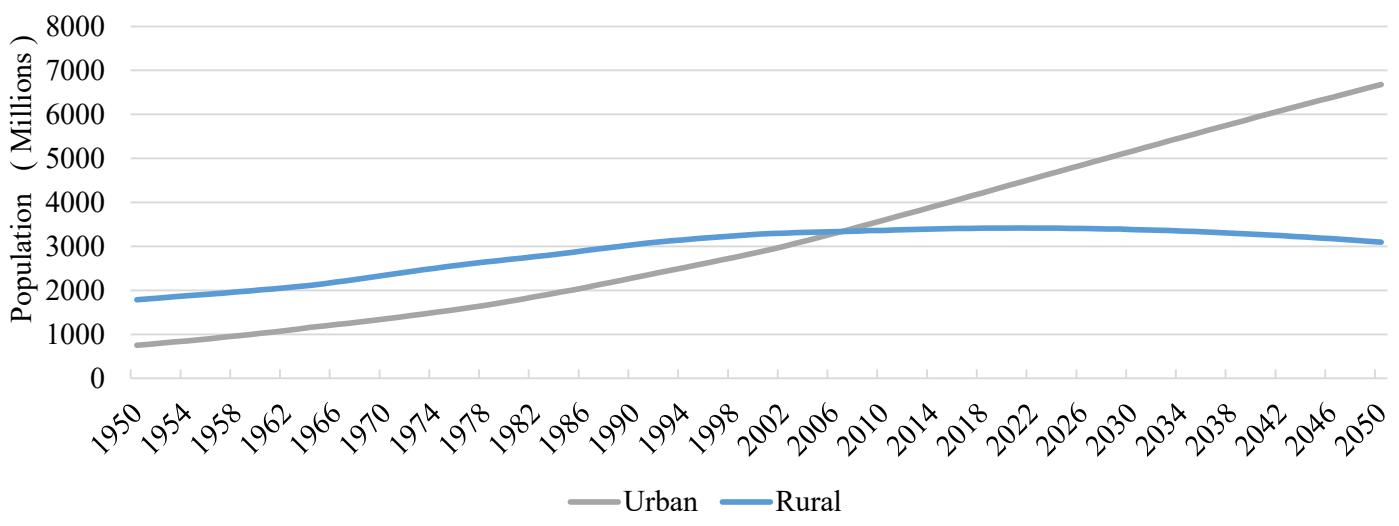

Figure 1. The world's urban and rural populations, 1950-2050. Data source: UNDESA 2014 [? ]. 


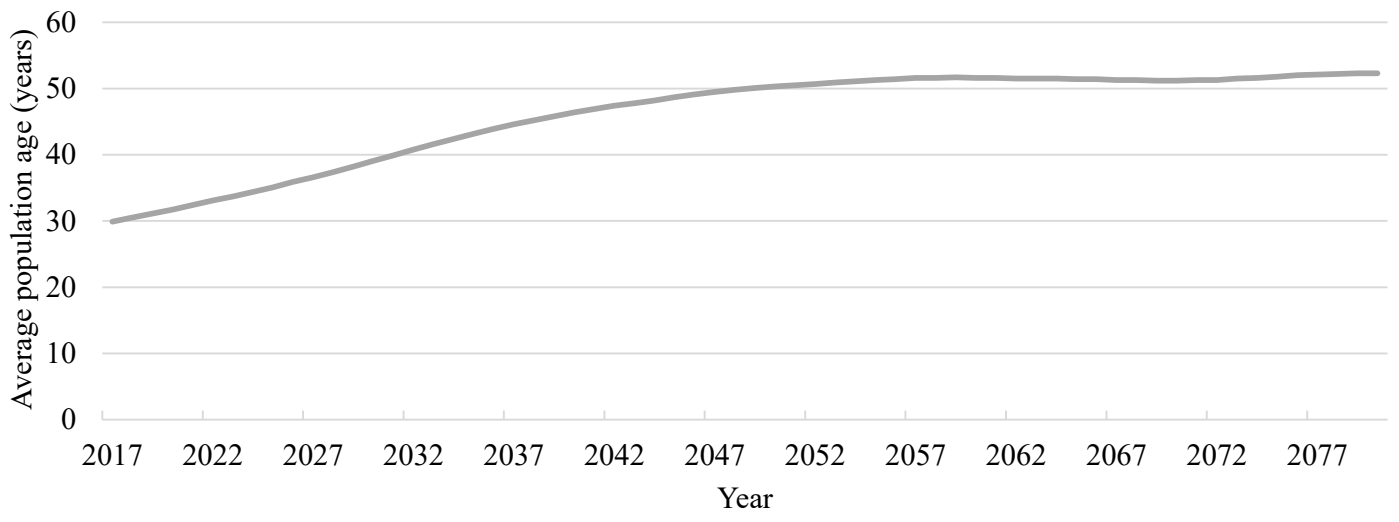

Figure 2. Projection of the average population age in the next 50 years, EU-28, 2016-2080. Source: Eurostat 2018 [?].

\section{Motivation}

According to the United Nations 2014 study (UN DESA, 2015 [? ]), two thirds of the world population will be living in urban areas by the year 2050 (Figure.1). Taking world population growth into account this means an increase of 2.5 billion people living in urban areas. The sheer number of inhabitants together with economic growth will lead to an increasing need for effective and cost-effective modes of urban transport.

Ensuring accessibility in urban areas means having space-efficient and affordable modes available for inhabitants. Densely populated cities are strongly dependent on high capacity trunk lines to be able to sustain the necessary traffic flow rates required to meet the travel demand. As trunk lines are not directly accessible by the whole population in any area, additional more flexible first- and last-mile solutions are required to feed and complement the aforementioned trunk lines.

While the world population is growing rapidly, the growth rate in Europe is much lower. The low growth rate leads to an ageing population, and Eurostat predicts the old-age dependency factor to increase in the EU-28 countries from 29.3\% in 2016 to 50\% in 2050 (Figure 2) (Eurostat, 2018)[? ].

Increasing automation is seen as one of the leading solutions to compensate the relative decrease in available workforce. The trend will also cause the traffic patterns to shift away from regular morning and evening peak hours, to more steady traffic around the clock as the significance of work trips declines. If successfully deployed, automated minibuses and similar automated vehicles can provide flexible and cost-efficient solutions for serving both peak and off-peak demand parallel to the trunk lines.

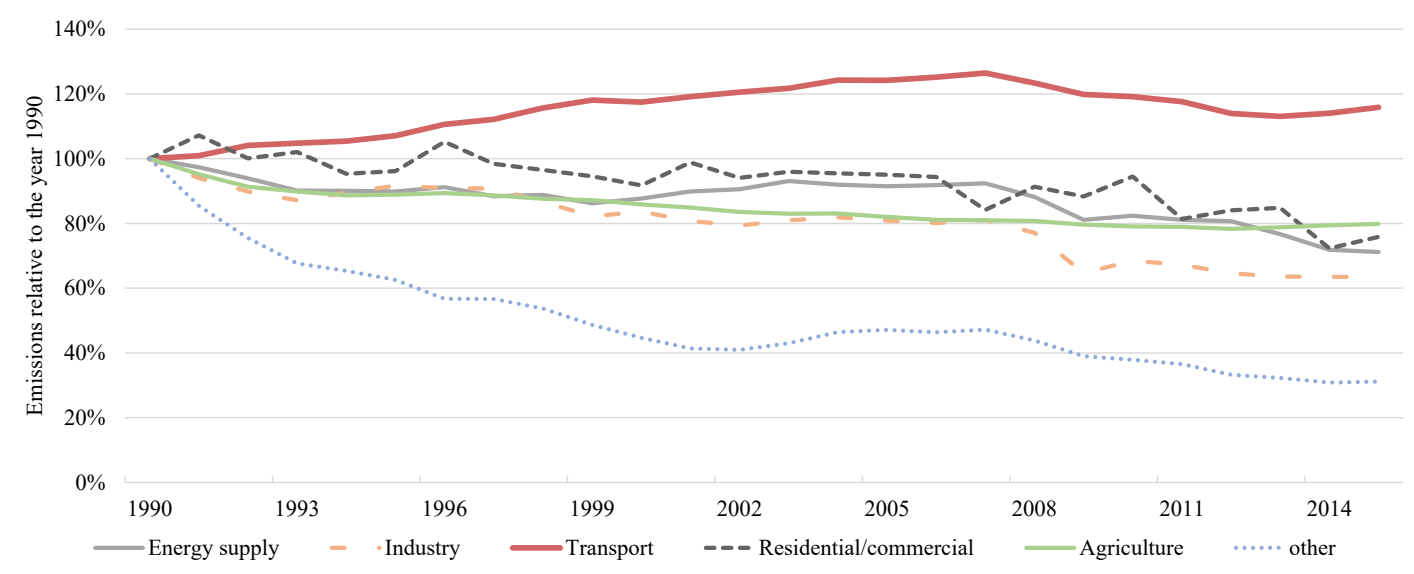

Figure 3. Greenhouse gas emissions by sectors relative to 1990 levels, 1990-2014. The contribution of transportation is labelled by the red coloured line. Data Source: EEA [? ]. 


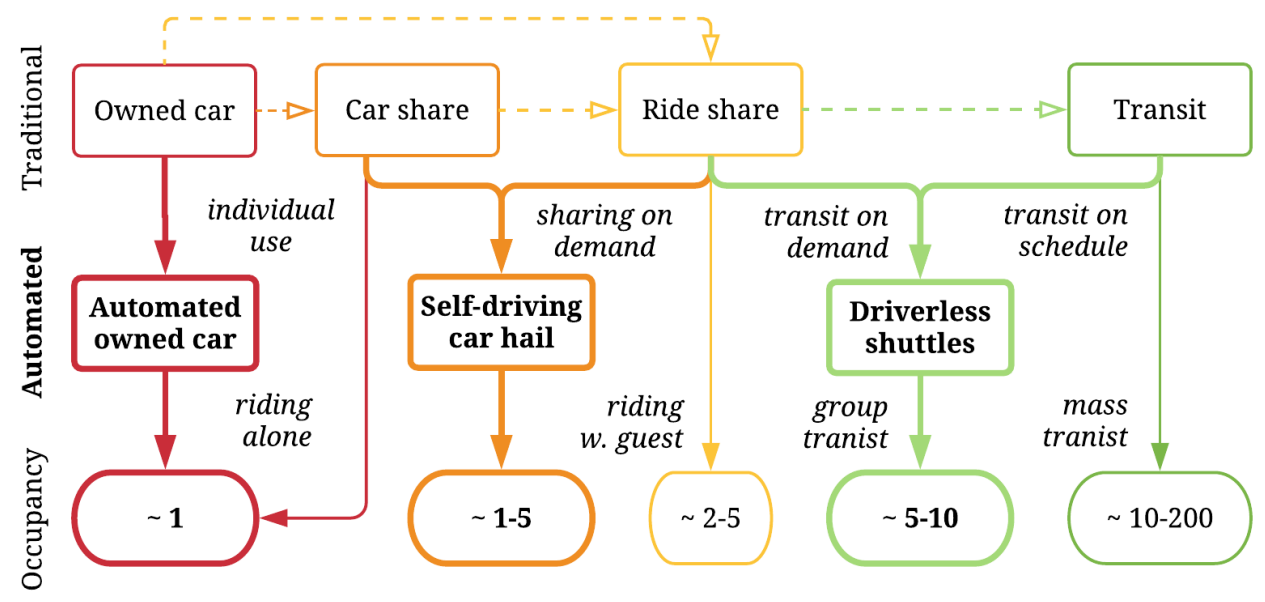

Figure 4. Simplified diagram based on [? ]. It presents a schematic representation of the possible consequences of implementing automated driving into four contemporary modes of transport: the automated self-owned car does not bring any change to the traditional car - it is still used mostly by one person (traditionally a driver, later a passenger); the self driving shared car can be used same way as an automated owned car, yet it can also merge with ride-sharing allowing more people to travel together (after the first rider acceptance), therefore it becomes more similar to the ride-hailing mode of transport such as taxi (but without a human driver); on the other hand, ride-sharing could merge with transit allowing on-demand travels but in smaller, more flexible driverless shuttles (minibuses); and the last, transit on schedule can also be provided by automated minibuses due to the lower cost of driverless services.

The EU has set a target to drop greenhouse gas emissions from transportation by $60 \%$ from year 1990 levels. Currently, the transport sector accounts for almost a quarter of the greenhouse gas emissions in the EU, and the reduction in this sector has been less successful than in other sectors (European Commission, 2016) [? ]. Electrification of road transport is seen as one of the most important steps towards carbon free transportation. The use of electric power will create high flexibility in terms of primary energy source and fostering full utilization of sustainable sources. In addition, electrified vehicles can operate indoors, offering new opportunities for innovation in city planning and transport routing.

The availability of autonomous public transport and new mobility services will increase the freedom to choose the most suitable mobility mode for each individual trip. By providing a wider palette of mobility solutions the users can lower their dependency on private cars and start using a wider spectrum of services. This can improve the resource efficiency and have a strong self reinforcing effect on the popularity of the mobility services, walking and biking.

According to a report from the European Environmental Agency [? ], the road transport is one of the main pollution factor in cities (Figure 3) and electric vehicles will help to dramatically reduce local emissions, including noise, particulates and other air pollutants in densely populated areas.

For private vehicles, advances in self-driving technology will improve the quality of the provided service with the final envision to enable the population without driving license, e.g. under-aged people, to access a car. The induced demand, wider user base and the vehicles driving without passengers will increase the number of cars on the streets [? ], [? ]. Although wide utilization of AVs (Autonomous Vehicles) and connected vehicles can help to significantly increase road capacity, the rapid inflow of new vehicles can, in some scenarios, lead to severe congestion. 


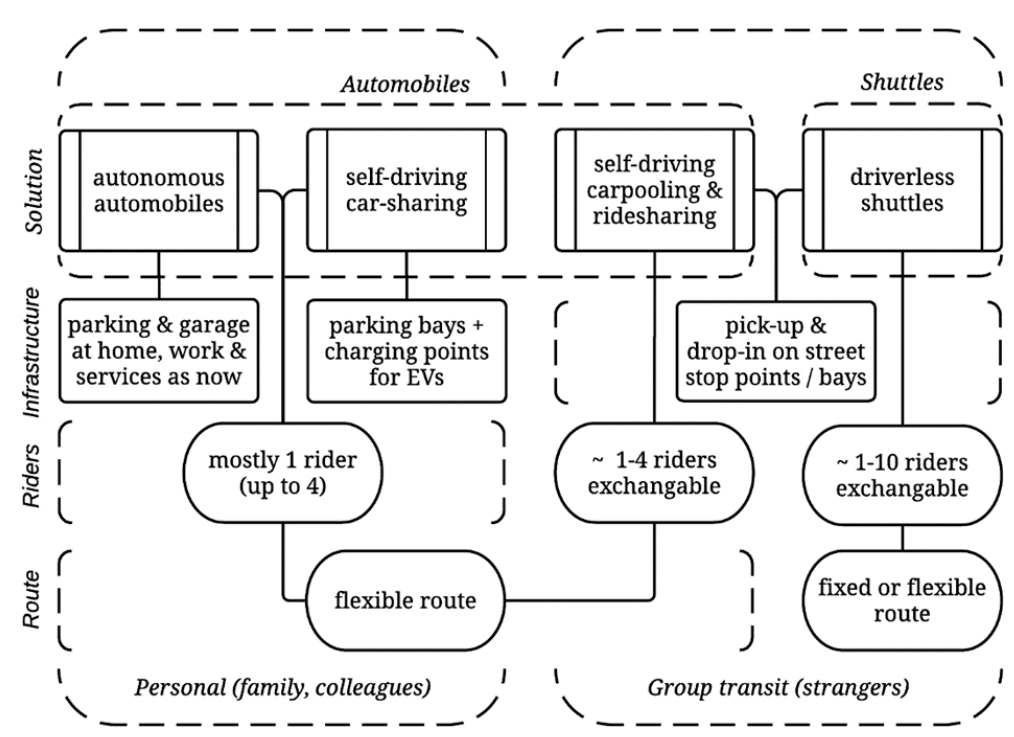

Figure 5. The diagram presents four solutions for automated modes of transport distinguished according to the infrastructure needed, number of commuters (riders), route flexibility and intimacy of travel. The self-owned mode, so-called "autonomous automobile" needs a parking and/or garage at home, work and near the everyday services, as it is today; due to the more often use of the self-driving car-sharing a few parking bays are needed, yet more charging points for electric vehicles are necessary; on the other hand, if self-driving ride share is used, pick-up and drop-in bays need to be prepared for this solution, as well as for driverless shuttles. The first two solutions are less efficient providing individual transport, or up to four travelling people who will probably know each other providing the feeling of safety; similarly self-driving ridesharing provides 1-4 places for commuters, yet the vehicle will exchange passengers more often (therefore they are strangers) providing para-transit mode; finally, the driverless shuttle provides space for about 10 exchanging commuters, who are unknown to each other. Most of the presented mobility solutions rides on flexible routes, yet it is possible that driverless shuttles will ride on a fixed route too. [? ].

In order to remain competitive, public transportation should be in the forefront of technological development. With correct planning and policies, communal AVs can help to improve mobility, leading to improved user experience, and reducing the number of vehicles in urban areas.

According to the survey distributed by the U.S. Department of Transportation (National Motor Vehicle Crash Causation Survey, 2008) [? ], the critical reason for accidents was attributed to the driver in a large proportion of the cases. Causes of crash include failure to correctly recognize the traffic situation, poor driving decisions, or driver performance drop. Sophisticated vehicle automation, while not perfectly safe, can help to mitigate or eliminate most of the 'human errors' related to the driving, and lead to a safer traffic flow for everyone.

\section{Variety of automated mobility}

Driverless shuttles (or autonomous minibuses) belong to the emerging group of automated mobility solutions [? ]. There are several differences between traditional over 100-year old mobility, and emerging automated solutions that may revolutionize riding and commuting (Fig. 4):

1. due to the absence of a driver, the ride-sharing/carpooling (Blablacar)/ride-hailing/sourcing (TNC Transit Network Companies: e.g. Lyft, Uber, taxi) merges with car-sharing (yet, we can still share a ride in the shared car);

2. mass transit, due to automation may be more effective travelling more frequently with less passengers, as well as being able to work in the on-demand mode, thus it is a more populated version of driverless car share, a driverless shuttle (or minibus); 
3. the self-owned and self-ridden car does not change much, instead of a revolution we will have an evolution of the traditional car which already can break, park or keep line autonomously.

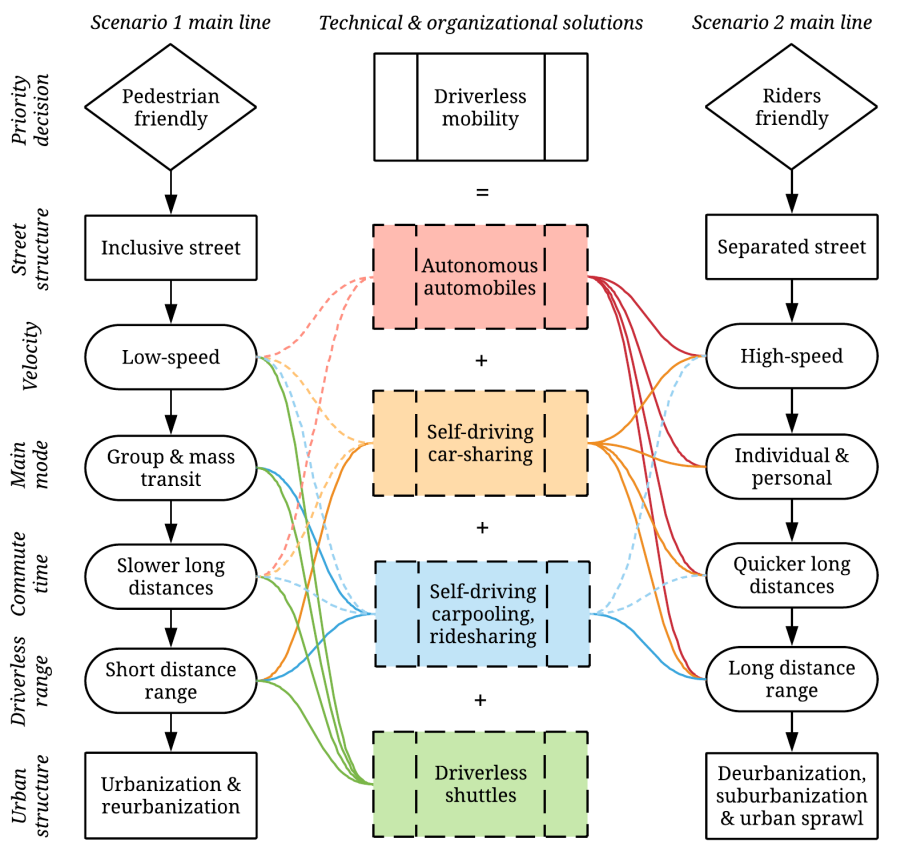

Figure 6. Relations between four automated mobility solutions, and two possible edge spatial-structures-development scenarios [? ]. Each strong relation is presented as a line, and weak relation as a dashed line. The so-called "pedestrian-friendly scenario" emerges due to the inclusive shared street structure, which reduces speed of vehicles, therefore the main mode of transport is a group or mass transit, thus it is less efficient for longer distances. As a consequence, it provides a short distance (first and last mile) driverless transportation which complements pedestrians and mass transit. This scenario has the strongest relation with the mobility solution of driverless shuttles. As a result, this scenario provides the sustainable development of urban structures, such as (re-)urbanization. On the contrary, the so-called "riders friendly scenario" emerges due to the separated street structure, which provides higher speeds of vehicles, thus generating popularity of individual and long-distance travels. This scenario has more strong connections with personal modes of automated mobility, such as the so-called autonomous automobiles or self-driving car-sharing, which results in inefficient way of the mobility and urban development, such as deurbanization, suburbanization and urban sprawl.

Following previous comparison, it is possible to distinguish four technical and organizational automated mobility solutions (actually three, considering merging of two middle solutions into one) presented in Fig. 5. These are: autonomous automobiles, self-driving car-sharing and ride-sharing or carpooling (both merging into one solution: self-driving, car-on-demand), and driverless shuttles. Of course, one can name them differently, and we will possibly see in the next decades which names emerge, and which get popular during their diffusion in society. What is worth to mention is that one can easily use the autonomous automobile without owning it, thus making travelling much easier, not only for drivers but also for people who are unable to drive. That also makes using a car more popular with all its positive and negative consequences. Self-driving car-on-demand is a cheaper and more efficient travel mode, but the question arises: who will share the car: previous car users or transit commuters? Thus, it could also have negative impacts reducing the number of public transit users.

Yet, the transportation authorities could introduce driverless shuttles (autonomous minibuses), which can compete with automobiles by price and be more effective than traditional mass transit, 
taking 10 instead of 150 passengers, being on-demand instead of on-schedule, and moving on flexible routes instead of a fixed routes, as well as being the first and the last mile connection to the mass transit.

Thus, one can consider two edge-scenarios concerning the diffusion of each technical and organizational of automated mobility solutions: the first is the pedestrian-friendly scenario which results in a street inclusiveness (emerging shared-street paradigm, like the Dutch "Woonerf" [? ]). The second is the riders-friendly scenario, which results in separated lines of various modes of transportation, and velocity of movement (continuation of the old 20th Century modernists' roads paradigm).

Clearly, the diffusion of each solution and emergence of any single scenario will depend on each other it is a relation of two, and a constant process. Therefore, it is important to remember that there are infinite possibilities between both presented approaches, and the final scenario could also emerge somewhere in between, depending on how close the edge would be.

Figure 6 presents also spatial consequences: the pedestrian-friendly scenario results in a sustainable urban development. On the other hand, riders-friendly scenario results in sub-urbanization and urban sprawl. But will the automated mobility lead to an increased urban sprawl? It will probably depend on consumers' decisions, also based on automotive industry advertising, as much as on public authorities' policy (politicians, transportation- and urban planners). If municipalities decide to promote a so-called "smart growth" by investing in driverless micro transit and in the reduction of parking, Scenario 1 will emerge. If automotive manufacturers would not have the competitors of self-owned autonomous automobiles, Scenario 2 will possibly emerge.

\section{Automated bus pilots}

The aim of this section is to provide an overview of ongoing automated driving pilots especially in Europe, and provide an understanding of common issues and concerns associated with such tests, and how they contribute to the deployment of viable solutions. The study will focus on how to leverage insights gained by others and discuss areas where experience, knowledge and result exchange would be helpful for large scale tests.

The number of autonomous shuttle pilots have increased rapidly over the last few years. These pilots have started to draw interest in various cities, universities and private companies. However, the objectives of the pilots may vary. In Europe, the autonomous shuttle pilots aim mostly to integrate themselves into the public transportation system. Switzerland, instead, is the most advanced country at the moment, as it has implemented autonomous shuttles to their public transport systems with regular timetables. Outside of Europe the pilots are still mostly about testing the technology and circumstances, or to look at the people's standpoint on autonomous vehicles. One of the biggest concerns, along with the technology performance, is to see how people accept autonomous shuttles. Legislation is also something that affects the success of pilot projects and, therefore, some of these pilots are carried out in private areas, where the conditions are rarely comparable to real scenarios.

Table 1 contains detailed information about pilots, that have been performed in open public roads with passengers, whereas in the following a summary for each relevant pilot is reported, including additional information according to the availability of sources. Most autonomous shuttles operate with a speed of $12 \mathrm{~km} / \mathrm{h}$, but some might go a little bit faster reaching $20 \mathrm{~km} / \mathrm{h}$. It should be noted that the overall documentation of the autonomous shuttle pilots is insufficient to provide a complete framework, hence the following information is to be considered as a rough review of the current situation.

\section{Bad Birnbach, Germany}

This pilot transfers passengers from the town centre to the spa area. The route is planned to be extended from the spa to the train station. Deutsche Bahn, the rail operator of Germany, is also planning to expand the operation of autonomous shuttles throughout the country. 


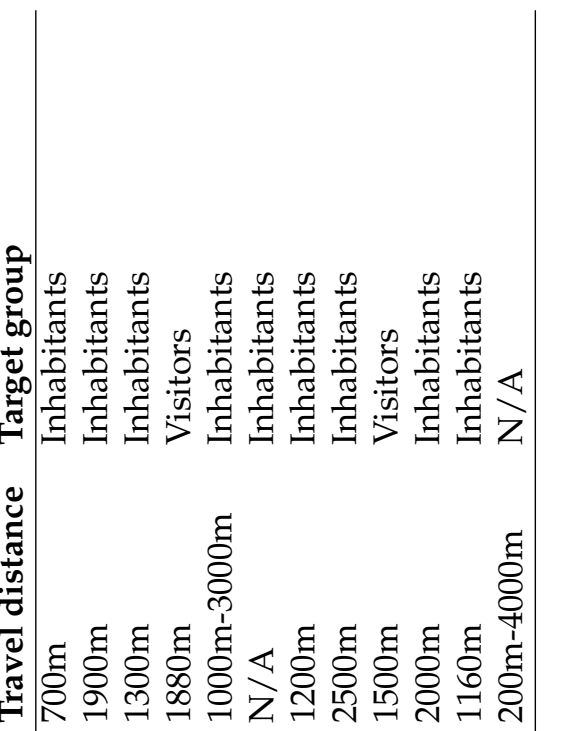

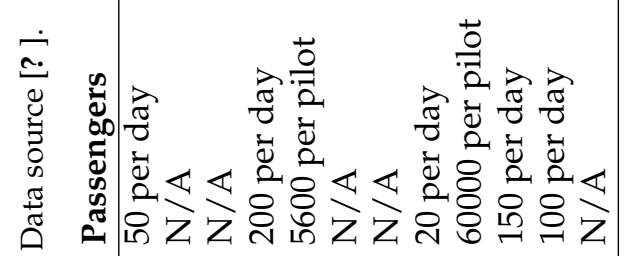

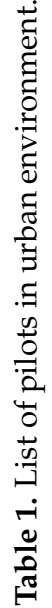

ֻे

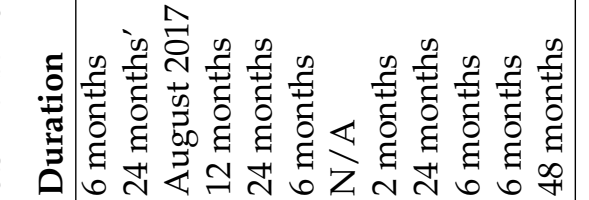

.

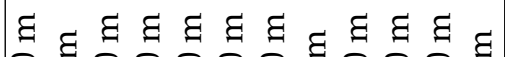

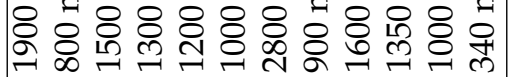

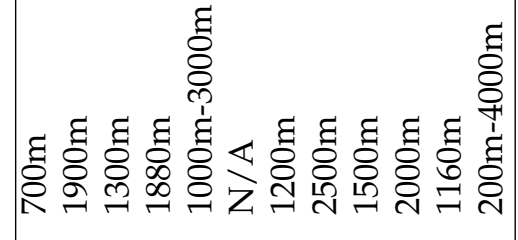

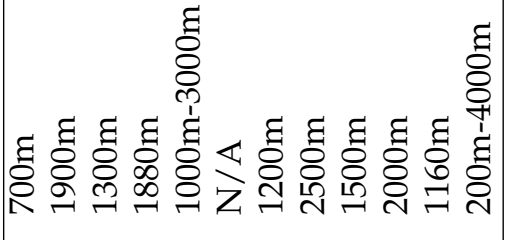

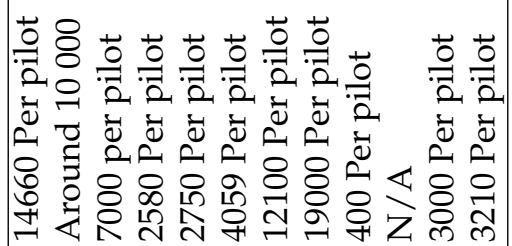

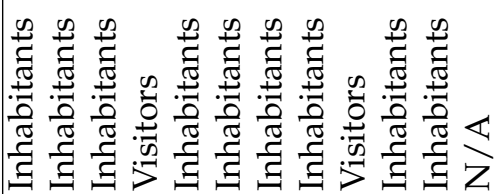<smiles>[C-]#[Fe]</smiles>

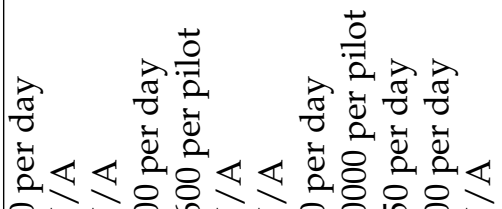

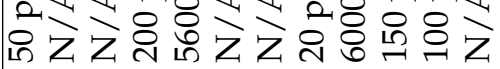

$$
\text { 葛 }
$$

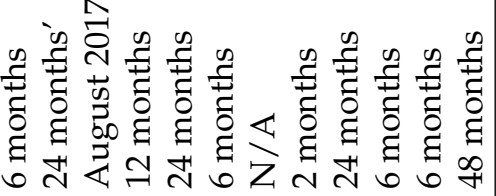
ह્વ

萨

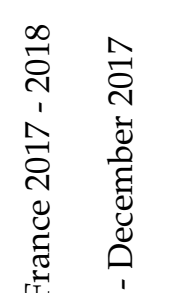

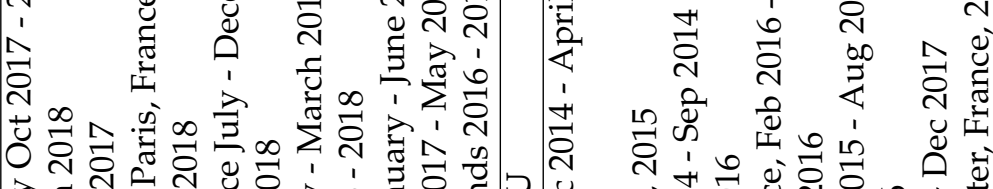

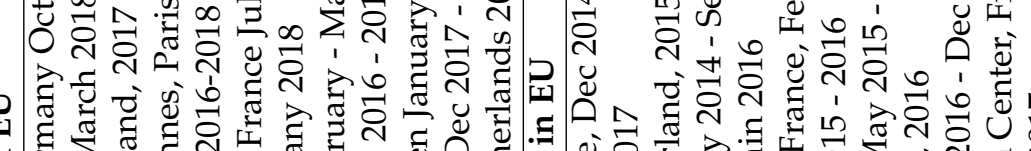

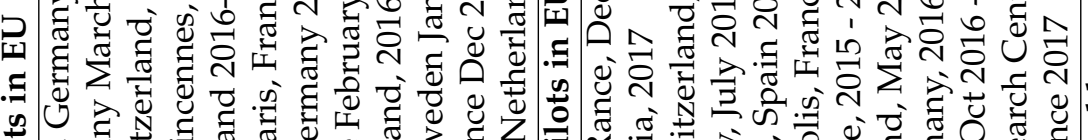

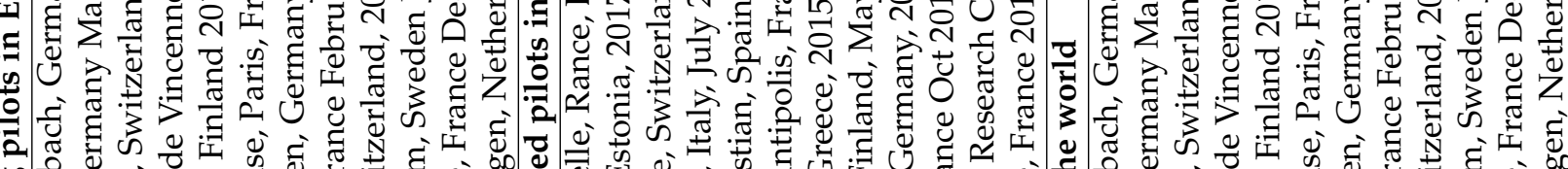
2.

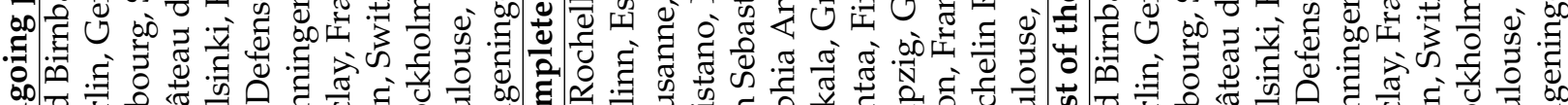
Oี 


\section{Berlin, Germany}

In Berlin, the Charité hospital campus and BVG, Berlin's public transit service, have launched a joint autonomous shuttle pilot from March 2018 onwards. The pilot consists of two routes aiming to carry students, patients and co-workers. For the first year, the shuttles will have an operator on board at all times, but from 2019 onwards, the shuttles are planned to travel without a member of the staff on board. The aim of the pilot is to study the effect of the introduction of autonomy on the use of the public transport, increasing the number of people using the service. The partners are also hoping to obtain information about passengers' acceptance of autonomous vehicles.

\section{Fribourg, Switzerland}

In Fribourg, the local public transport company, Marly Innovation Center, and different public actors have launched their autonomous shuttle pilot to connect the Marly Innovation Center area to the public transport service. The pilot started in September 2017, and and it was available for passengers from December 2017 onwards. The primary objective of this pilot is to transport commuters to their work place. Another objective is to connect the residents of the area to urban public transport network. This new connection is hoped to attract new business to the area. This is the first regularly operated autonomous shuttle in Switzerland. During the peak hours, the shuttle runs at every 7 minutes, and the vehicles will eventually operate on demand, and an operator will be inside at all times. The vehicles adaptation to road traffic is seen as a challenge. Therefore special arrangements have been agreed on between the different partners. This pilot is hoped to provide information whether this kind of system could be exported to other parts of the canton of Fribourg, and it has already raised interest in various federal offices due to the possibilities that autonomous shuttles could provide for isolated areas.

\section{Château de Vincennes, Paris, France}

The aim of this pilot is to connect the nearby metro station, and the culture and entertainment area together. Prior to the pilot there were very poor connections in this 2 kilometre distance, hence the length of the route is planned to be extended in stages. The issues of this pilot are described to be crossroads, increased speed, and progressive insertion into the traffic. The pilot is also aiming to explore platooning with autonomous shuttles to solve the problem of traffic peaks. The ultimate goal of the pilot is to be able to operate a number of autonomous shuttles adapted to the flow of users.

\section{Helsinki, Finland}

The first autonomous shuttle pilot of Finland, that was carried out in open public roads, is called SOHJOA. Within this pilot, a couple of robot buses have been operating in three different Finnish cities. The objective was to learn how autonomous shuttles adapt to harsh winter conditions, but it became clear that the technology is not yet advanced enough. Another objective was to provide a platform for Finnish companies to develop and test their products and services. Example of these was a logistic company which piloted package delivery around the pilot district of Espoo. SOHJOA faced challenges as it was not allowed to modify the shuttle in any way. This pilot provided also some information on how people received this kind of a vehicle. The information was collected by a survey. All in all, SOHJOA provided a comprehensive understanding, what it is that these autonomous shuttles require to operate and function in mixed vehicle traffic on public streets.

\section{Tallinn, Estonia}

Tallinn pilot, that took place during EU Presidency, received positive attention. The pilot with two Easymile buses for three summer months in 2017 was initiated by the Government Office, Ministry of Economic Affairs and Communications in collaboration with the private sector (Milrem, Easymile, DSV, Tallink). The pilot took place in Tallinn downtown close to the Old Town and Old-Harbor. The main issues were related to procurement and operation. For example, the buses failed to recognize 
traffic lights and pedestrian crossings had to be taken over manually each time. The pilot was operated by the local company Milrem and they carried thousands of travellers.

\section{La Defense, Paris, France}

La Defense is a business district in Paris where 500,000 people travel to and from work every day. The three shuttles of this pilot are operating in pedestrian areas only. People in this area have quickly adopted this new mobility option. The shuttles depart every 10 minutes during peak hours, and in the off-peak periods every 20 minutes.

\section{Sion, Switzerland}

The pilot in Sion is called SmartShuttle, and it contains two shuttles operating between historical sites of the town. The shuttles are operated remotely, however due to legislation an employee on board. The pilot was executed to examine whether the autonomous shuttles service is technically and operationally feasible in the public space, and if it offers an additional value to the customers. The pilot is planned to supplement existing transport options. There is a plan to extend the pilot and conduct a study to understand how people feel about autonomous shuttles.

\section{Stockholm, Sweden}

Stockholm launched their 6 month pilot in January 2018. The pilot is managed by Nobina, the biggest Nordic transport company. The project is part of Test Site Stockholm, a research program based at KTH Royal Institute of Technology's Integrated Transport Research Lab. The area of the pilot is called "Scandinavian Silicon Valley". The aim of the pilot is to eventually implement these shuttles into their public transport system.

\section{Toulouse, France}

There have been two pilots in Toulouse. According to a study made within the first one, the autonomous shuttle was really well received by the passengers. $97.5 \%$ of respondents found the shuttle comfortable and the driving pleasant, $78.5 \%$ of users felt safe aboard the shuttle and $90.5 \%$ of people would have boarded even if there was no operator. The second pilot aims to remove the operator from the shuttle, therefore it has been divided into three phases. In the first phase, the operator will be on board, but in the second phase the operator will only follow the shuttle from outside. In the final stage, the operator will be removed altogether.

\section{Wageningen, Netherlands}

Wageningen launched a pilot which consists of two autonomous shuttles. These shuttles travel between the city's railway station and the Wageningen University \& Research campus. The city officials have outlined, that the lesson to be learned from this pilot is the need for cities to clarify the learning goals for autonomous shuttle pilots, and how important is to communicate the experimental failures as well as successes. In Wageningen, it is seen as important that the cities take a leading role in the development of autonomous shuttles, rather than the industries.

\section{CityMobil2}

Cities and pilots of CityMobil2 EU-funded project varied greatly. However, all the cities and pilots had the same objective; to adapt autonomous vehicles to be a part of the public transport system. The aim was also to do an assessment of the vehicles' transport, environmental and economic performances. As the most important project carried out until then, CityMobil provided a comprehensive set of conclusions regarding the implementation of ARTS and the barriers to overcome: the lack of an implementation framework for cities, absence of a specific legal framework, and the unknown wider economic effect. Overcoming and removing these barriers were the main objectives of CityMobil2. 
Furthermore, the pilots gathered information on acceptance, vehicle performance and interaction with other road users.

\section{Lyon, France}

This pilot is said to be the first regular service provided by autonomous shuttles, and it inspires many other pilots in France. Navya created a mobile app for the passengers to know where the shuttles are located on their route in real time and to consult the schedule.

\section{Airport Weeze, Germany}

An important part of the project "Interregional Automated Transport - I-AT" in Interreg A is the (further) development of technical innovations and solutions for the automotive and logistics sector, especially in the areas of automation, information and communication technology, artificial intelligence, measurement and sensor technology. The testing of prototypes in the German-Dutch border region will enable important progress in autonomous driving. The test operation with autonomous vehicles (WEPods) is to take place at Weeze airport (car park shuttle) and in a cross-border transport corridor (for example Aachen-Vaals). In the project, research institutions, large enterprises, SMEs and public institutions from the region are working closely together to promote knowledge transfer and product innovations in the German-Dutch border area and to strengthen the regional economy.

\section{Munich, Germany}

In the project "Optimized transport system based on self-propelled electric vehicles" - funded under the "Eneuerbar Mobil" funding program of the German Federal Ministry for the Environment, Nature Conservation and Nuclear Safety (BMUB) - an autonomous and electric vehicle will be developed. The vehicle will be tested in Munich Perlach in the middle of 2018. OTS most important feature is the inclusion of information from permanently installed infrastructure for the observation and evaluation of traffic, including transmission of the information to the vehicle (car-to-infrastructure). This approach promises additional safety for autonomous driving and a better traffic flow compared to systems with only vehicle-based sensors. The aim of the project is to examine concrete approaches for future mobility concepts (infrastructure and vehicle) and their business models.

\section{Hamburg, Germany}

The project HEAT (Hamburg Electric Autonomous Transportation) will create visibility for autonomous driving with emission-free shuttle buses in a first test area in Hamburg's HafenCity. The aim is to prove that a fully automated or autonomous vehicle system (SAE level 5, i.e. without driver) can be integrated into regular road traffic. The goal is to develop, test and deploy electric autonomous vehicles and systems.

\section{Osnabrück, Germany}

Together with the partners Stadtwerke Osnabrück, the Innovation Centre for Mobility and Societal Change (InnoZ), Kompetenzzentrum ländliche Mobilität Wismar (KOMOB), the German Aerospace Center (DLR) and HaCon, a distribution platform is to be established within the project period, which, in combination with a mobility platform for customers, enables the interconnectedness of the on-demand traffic offer with a central bus line both for the transport company and for the customer. In addition, the developed platform is also to be applied to an autonomous vehicle.

\section{Future pilots}

The number of autonomous pilots is increasing, and part of them are currently under development. Table 2 reports a summary of not yet started pilots, which will be operated in public roads with passengers. However, this is incomplete, since no institution have already compiled a 
comprehensive list. The closest equivalent would be Bloomberg Philanthropies and the Aspen Institute which provide a rather inclusive overview of the cities testing autonomous vehicles (https://avsincities.bloomberg.org/).

Table 2. List of pilots which will start in the next future. Data source [? ].

Adelaide, Australia (N/A)
Calgary, Canada (2018)
Copenhagen, Denmark (2018)
Gainesville, US (2018)
Gothenburg, Sweden (2018)
Hamburg, Germany (2018)
Knoxville, US (2018)
London, UK (N/A)
Gjøvik, Norway (2018)
Drammen, Norway 2020
Tallinn, Estonia (2019, 2020-2022)
Vienna, Austria (2019)
Gdansk, Poland (2019)

Oslo \& Gjesdal, Norway $(2018,2019)$

San Francisco, US (2020)

Stavanger, Norway (2018)

Sydney, Australia (2018)

Christchurch Airport, New Zealand (2018)

Melbourne, Australia (2018)

Ann Arbor, Michigan, US (2018)

Shenzhen, China (2018)

Kongsberg, Norway (2018-2019)

Vejle, Denmark (2019)

Koppl, Austria (2018-2020)

Helsinki, Finland $(2018,2019,2020)$

\section{Technological background}

Autonomy and electrification constitute enabling technologies for the next generation of the transportation system. In this section, these two concepts will be reviewed according to the recent state of the art.

\subsection{Electrification of transportation}

Industry and research are working together toward the electrification and automation of urban vehicles thanks to its potential to reduce pollution. Unfortunately, full electrification is not to be considered fully-economically convenient yet, due to the high costs of batteries and the low energy density of electrochemical storage compared to fossil fuel, but fortunately automation and intelligent technologies are contributing to approach this ambitious target by increasing the global efficiency of vehicles. Indeed, energy efficiency is currently one of the most important topics in the road vehicles industry.

As reported in Fig. 7, road transport is responsible for emitting over 1 billion tonnes of $\mathrm{CO} 2$ annually, which accounts for about $24 \%$ of global greenhouse gas emissions. Even more relevant is the amount of SOx and NOx emissions [? ], [? ]. Indeed, a Euro 5 diesel passenger car NOx emissions

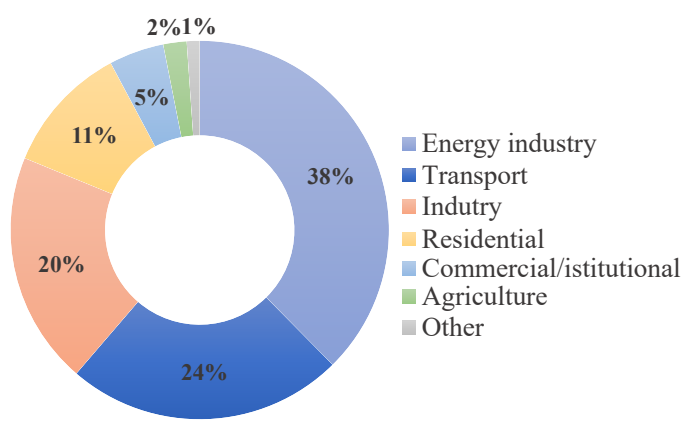

(a)

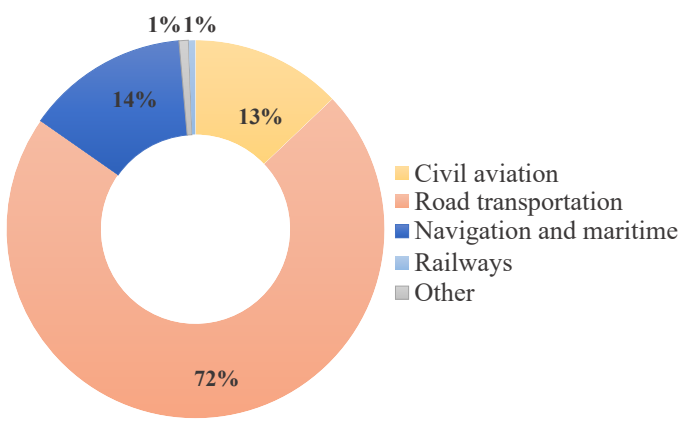

(b)

Figure 7. Impact of $\mathrm{CO} 2$ emissions in 2012 by sector in EU-28. The global CO2 emissions, in percentage, are shown in (a); whereas the specific contribution of the transportation sector is reported in (b). Transport causes $24 \%$ of total emissions, $72 \%$ of which comes from road transportation. Data Source: EEA [? ]. 
range between $430-810 \mathrm{mg} / \mathrm{km}$ in real driving conditions. This clearly shows the necessity of moving from private car-based transportation to public-based electric transportation.

The full-electrification of the public transportation system requires both vehicles and infrastructure to adapt to the new concept. The infrastructure should be updated with new charging stations around the urban areas, whereas vehicles should be equipped with high-density batteries. An important aspect of the recharging infrastructure concerns the choice between a unique station (centralized architecture), or the installation of many small charging points in each parking lot (distributed architecture). In most of the studies, the predominant direction is toward a decentralized architecture [? ], [? ]. In [? ], the authors compare centralized and decentralized architectures in simulation, concluding that a decentralized method would be more effective, also in terms of costs. However, they neglect a few important parameters such as the possible overloading in the electric grid due to too many vehicles recharging at the same time in the same area. Such a connection can be either wired or carried out in a wireless manner using magnetic inductors. The solution features the magnetic inductors at the bottom of the minibus and on the ground surface of the parking lot. As indicated in Fig. 8, both systems could coexist in the minibus, where an automatic switch can select the power source based on the specific situation and location.

The basic components for the electrification are: Electrical motors, battery packs, AC/DC and DC/AC converters for recharge and power, cooling systems, cables and safety components [? ]. Fig. 8 provides a schematic example. From a vehicle point of view, the electrification would bring countless advantages in terms of pollution reduction, heat generation, noise in urban areas and safety. However, the main lack in the use of batteries versus fossil fuels for transportation purposes is the lower energy density in electrochemical storage, defined as the amount of energy per mass. More specifically, the energy density in diesel is roughly $13,440 \mathrm{Wh} / \mathrm{kg}$, whereas a Lithium-ion battery has an energy density around $220 \mathrm{Wh} / \mathrm{kg}$ [? ].

This means that over 60 times the weight in batteries should be needed to obtain the same amount of energy of fossil fuel. Fortunately, electric motors have a higher efficiency (over 90\%), in contrast to combustion engines which have an efficiency less than $30 \%$ in optimal conditions and which goes below $20 \%$ in normal usage. From a reasonable estimation the additional weight can be between 10 and 20 times. This calculation does not pretend to be a precise estimation of the weight on board which may depend on vehicle specifications, but it gives the idea that batteries constitute an additional weight. As the efficiency of the electric motor is quite high, the efforts are currently concentrated on increasing the energy density and the efficiency of the recharging process. Following this line of research, the scientific world is investigating materials with high electrochemical energy density, going from old lead acid batteries [? ] to Li-ion batteries [? ], and even Lithium-air batteries [? ], which are expected to operate in the next decades with energy density comparable to fossil fuels.

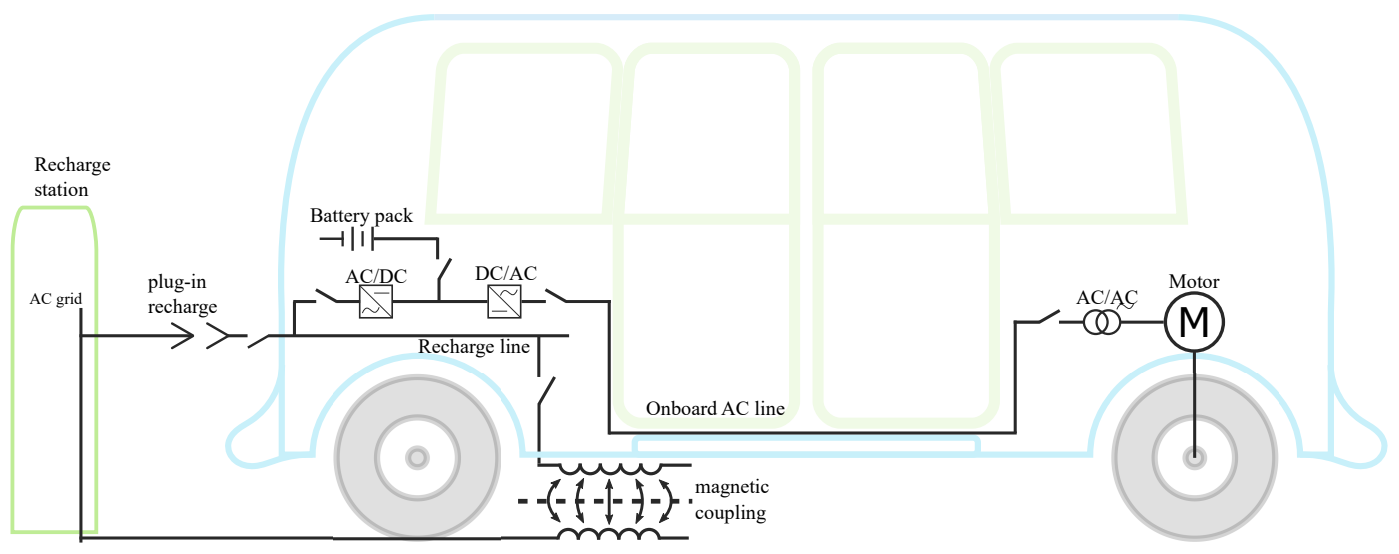

Figure 8. Schematic of typical electrification components in electric buses. 


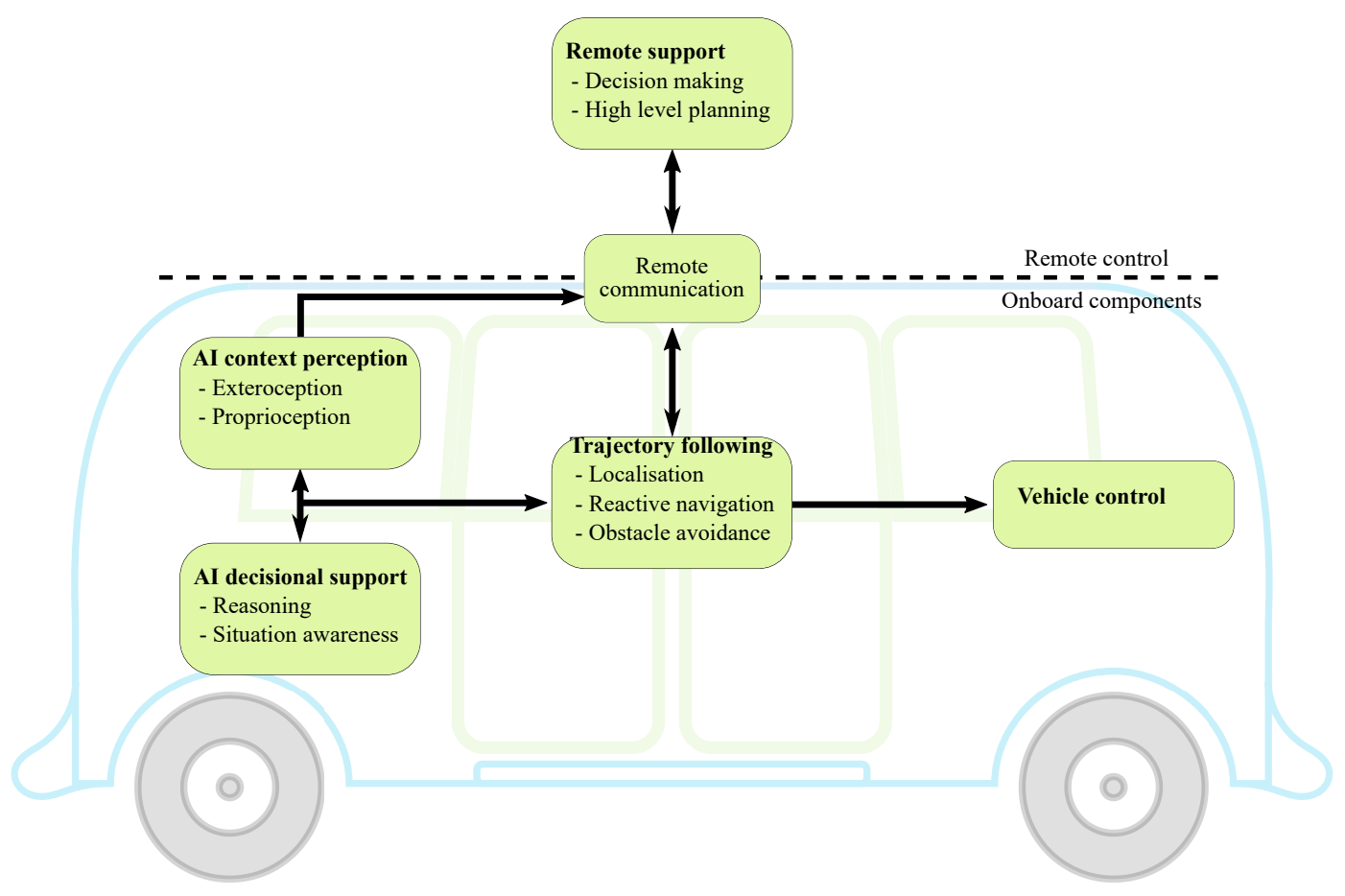

Figure 9. Main elements for situation awareness of an automated bus.

One of the challenges in the field of Li-ion batteries is a phenomenon so-called "dendrite formation" [? ], i.e. small spikes in the lithium anode, which cause short circuits between anode and cathode [? ]. Although far from the market, a possible solution is to protect the anode using a graphene layer reducing the problem of dendrites and promising high energy density around 1,000 $\mathrm{Wh} / \mathrm{kg}$ [? ]. Furthermore, a recent research on the same technology promises to triplicate the energy density of graphene-based batteries using an additional silicon layer [? ]. According to the US. Geological survey there is enough Lithium, in the United States only, to equip over 30 billion vehicles worldwide with Lithium-ion batteries [? ]. The current costs of Lithium carbonate, required for batteries, is around $10 \$ / \mathrm{kg}$ with increasing trend due to the increasing market request. The other materials composing a lithium-ion battery such as cobalt oxide, manganese oxide, copper, and aluminium, are also inexpensive and common in nature.

\subsection{Autonomy in urban transportation}

In order to achieve the ambitious goal of safe fully autonomous driving within urban areas, vehicles have been equipped with a large number of sensors, essentially converting a normal car into a type of robot, adding new functionalities for control such as perception and artificial intelligence (AI) [? ]. These basic concepts referring to the state of the art technology of autonomous driving are still controversial and discussed in the recent literature. For instance, which specific models of sensors and perception systems to use, or whether to use a precise model-based or an artificial intelligence approach to solve the problem of autonomous driving from end-to-end [? ]. The latter approach copes with the problem as a whole using artificial intelligence.

The problem of automatic control of any system has been historically addressed using the classical control theory [?], that copes with the problem using the procedure of analysis of the physical process and synthesis of a controller [? ]. Only if the physical process to be controlled is completely known, the synthesis of the controller can be solved. In case of autonomous vehicles the physical behaviour can change significantly according to the geometry of the vehicle, the load and the surface friction (for instance in case of rain or snow). A precise model that takes into account the number of variables analytically to synthesize a controller is often considered too complicated to be treated with the 
classical theory. The process models of a wide number of vehicles are currently well approximated and implemented in market available advanced driver assistance systems (ADAS), such as cruise control, automatic braking, and lane keeping assistance [? ]. However, a system built using the classical control theory lacks of reasoning, which is a required feature to build a fully-autonomous vehicle. On the other side, the artificial intelligence approach considers the vehicle to be a black box, and it automatically builds million connections between input and output removing the processes of analysis and synthesis of the controller.

The approach is demonstrating efficacy in many practical scenarios, showing a high adaptation and abstraction ability. The work needed to synthesize such a control system is mainly based on large amount of data acquisition and labelling to build known connections between input and output of the system [? ]. Using machine learning, tasks such as scene recognition and situation awareness become solvable, giving to the vehicle the required level of reasoning. Although end-to-end approaches exist, they are somehow considered too abstract, removing the entire knowledge of the systems from the design, by replacing it with a black box, resulting in difficulties in detection and solving possible failures. As a result, the most reasonable approach does not exclude one or the other, but rather includes classical low-level control and artificial intelligence high-level reasoning used to support decision making. The real debate resides in the question: at which level should artificial intelligence be implemented? The most conservative streamline of research foresees the AI features to be placed at the higher possible level, limiting their task to scene recognition, such as pedestrian/cyclist/vehicle detection and in general obstacle recognition. Other approaches add artificial intelligence also for reactive navigation and obstacle avoidance, starting to include AI features into the high-level safety. Low-level control and safety are still implemented using the classical control theory.

The schematic in Fig. 9 describes the main components required for safe autonomous driving of buses. Onboard components include AI for perception and decisional support, sensor data must be properly interpreted in the specific context providing reasoning abilities. Such interpretation is used for trajectory following, performing tasks such as obstacle avoidance and reactive navigation. The trajectory following also requires the localization ability to estimate the current position of the vehicle on the road. The most basic level is the vehicle control featuring low-level control architectures for acceleration and steering commands. Even though a remote station with the tasks of high-level planning and decision making should be included, most of the automation should be embedded on board. Indeed, while for tasks involving a small number of vehicles the autonomy using a centralized station with remote control is realizable, with a high number of driverless buses in an urban environment the complexity increases at a level that a centralized approach becomes infeasible due to the number of vehicles on the road. However, the communication between remote support and autonomous vehicles is important for the stability and efficacy of the entire transportation system. The remote support of decision making may include cloud computing for artificial intelligence support, this to access a large amount of data for interpretation and classification.

\subsection{Sensors and perception}

Vehicles are nowadays equipped with many different sensors that monitor the internal status like engine rotational velocity, temperature, global velocity etc. The main feature that distinguishes an autonomous car or bus is that its own absolute position and the surrounding environment have to be measured. There is a distinction between proprioceptive sensors and exteroceptive sensors, referring to the measurement of the internal vehicle status and the surrounding environment. In this section, a review of the main sensors and technologies used to integrate perception in autonomous vehicles will be reviewed.

\subsubsection{Localization}

The great strides of steering and velocity control systems allow vehicles to have a precise desired behaviour, but the driving policy must be defined according to up-to-date dynamic information 


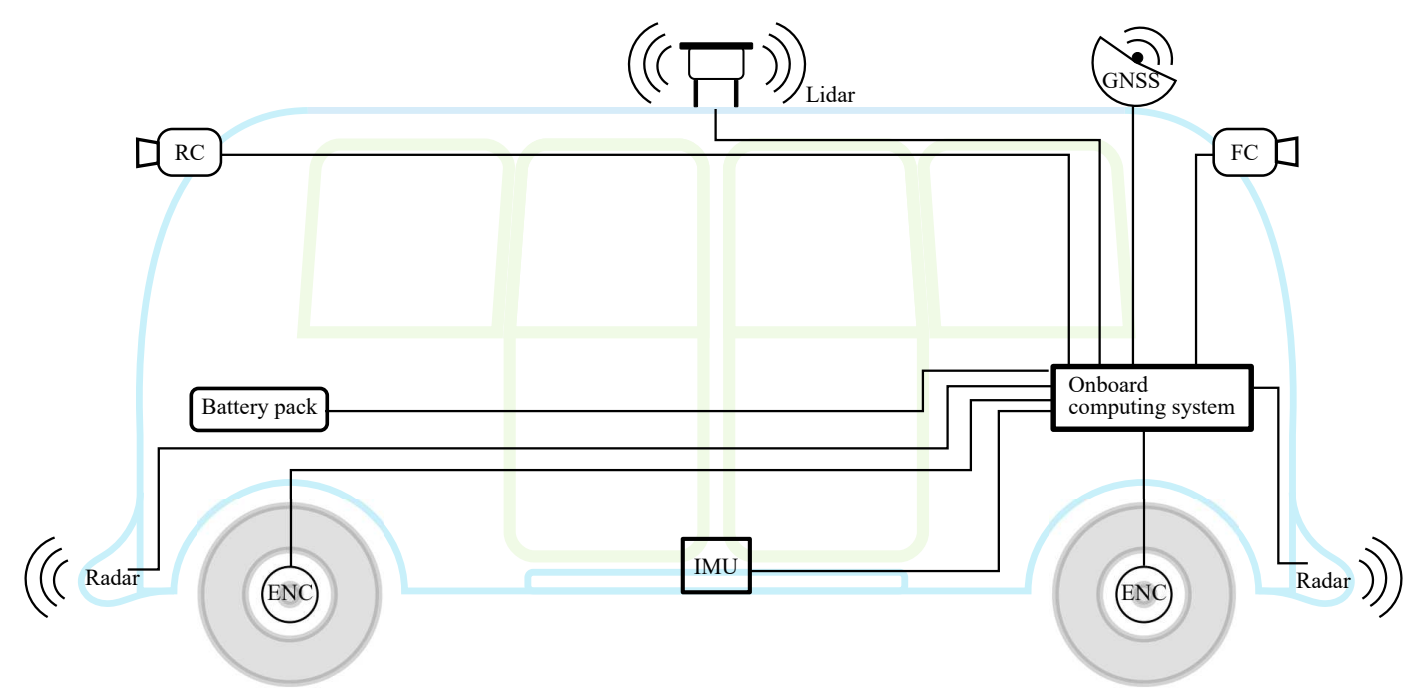

Figure 10. Typical sensors components for an electrical autonomous minibus. Sensor list: IMU, GNSS, Laser, $\mathrm{RC}=$ rear camera, $\mathrm{FC}=$ front camera, $\mathrm{ENC}=$ encoder.

(i.e. current pose and speed), which should be known or measurable with reasonable accuracy in order to navigate safely. In the field of ground vehicles, navigation is referred to as "every process or activity of accurately ascertaining one's position and planning and following a route" (source: oxford dictionary definition). Although this definition derives from the ancient meaning of travel on water, it completely fulfils the current connotation used in autonomous cars, underling the three main aspects bound to vehicles' movement, i.e. self localization, path planning and trajectory following. The integration between localization, planning and following constitutes a navigation system. According to its capabilities, one can distinguish between fully-autonomous or semi-autonomous navigations systems.

In the view of the plurality of related applications, navigation methods may change according to the vehicle's workspace and sensors. Hence, indoor navigation is generally assigned to odometer sensors and visual techniques, whereas Global Navigation Satellite System (GNSS) generally accomplish the task of localization in outdoor environment. GNSSs estimate the position of a device on the Earth by trilateration of the signal from satellites in different orbits [? ], [? ]. Satellite-based navigation theory constitutes a wide and deep field of study and involves a large number of standards and notations. One of the most used is the World Geodetic System 1984 (WGS84), that constitutes an Earth-centered fixed terrestrial reference system [? ]. In spite of GNSSs based localization systems fit really well a large spectrum of applications in mobile vehicles, their accuracy may range within few meters, whereas most of applications in the automated driving require centimeter accuracy. Such precision is achieved using a base station. The GNSS is capable of measuring its distance from the satellites and the base station as well, improving the vehicle's positioning precision. This technique is also known as Real Time Kinematic, or RTK, and widely used in the field of vehicle-to-vehicle relative positioning [?].

Moreover, GNSSs need the direct connection between a receiver on the Earth and more satellites at the same time resulting in loss of accuracy in the case of hidden satellites, e.g. the so-called urban canyons, i.e. city roads surrounded by tall buildings [? ]. To increase the global localization accuracy, researchers' studies are moving toward the integration of GNSS technology with visual odometer systems. As a further issue, GNSSs perform really well in determining the global coordinates of a vehicle, but they cannot determine the exact pose of a vehicle including its orientation. At this aim, GNSSs are now integrated with Inertial Measurements Units (IMUs), or Inertial Navigation Systems (INS) [? ], [? ]. An IMU is a device able to measure vehicles' angular velocities, their orientation and gravitational forces by means of a combination between an accelerometer, a gyroscope and a 
magnetometer. One of the most used indirect sensor approach is the so-called dead-reckoning, which implies the integration of sensor measurements, typically the wheel encodes and IMU, to derive the current pose of the vehicle integrating wheel velocity information. The biggest limitation of dead-reckoning techniques resides in the unbounded accumulated error. In contrast, a direct sensor approach would offer the most accurate measure of the state of a vehicle, unfortunately some of the variables are not directly observable. Even though a GNSS can directly measure the vehicle position, the update frequency is typically low, varying in the range $1-20 \mathrm{~Hz}$.

The important task of localization can also be approached from another perspective. Humans are able to localize themselves using space recognition capabilities, i.e. we use our own eyes to recognize salient attributes in space, and we locate ourselves in it. This implies the use of visual capability to improve global positioning. Most of the market players are exploring this way by using visual cameras and lasers to reconstruct the surrounding space and locate the vehicle in it. This technique is also known as SLAM or simultaneous localization and mapping [? ], [? ], and it consists in the estimation of both the map and the robot location at the same time based on visual data. In other words, the vehicle needs to build a map of the environment while navigating through it. The most recent research on SLAM brought this method toward the mapping of wide geographic areas, indeed probabilistic methods improve the global performance of the alignment such as the use of an extended Kalman filtering for the motion estimation [? ]. One of the biggest problems with SLAM is the un-bounded error that increases over time. A widely used way to increase the accuracy of the mapping is the so-called Loop Closure [? ]. This technique attempts to correct the alignment error every time that the estimated position of the robot is close to a previous driven position, as well as a loop [? ]. Some market players (for instance Navya buses) decide to rely more on satellite-based localization, whereas others use more SLAM for the localization (EasyMile buses for example).

\subsubsection{Scene interpretation}

The analysis of the surrounding environment is performed in autonomous vehicles using visual cameras and 3D sensors for space reconstruction. The important task of these sensors is to reproduce the human eyes with robotic vision [? ], giving the vehicles the ability to detect objects on the road. Normal visual (monocular) cameras can acquire 2D images, which makes it hard to have accurate direct distance measurements without adding a post-processing and, as a result, additional computational burden. Indeed, camera images constitute a projection of the 3D reality onto a 2D plane, and, for this reason, the distance information is lost during the acquisition. A way to retrieve this information is to measure the difference between two images from different angles, but at least two cameras would be needed. Considering that an autonomous vehicle would be moving, it is possible estimate the distance of objects by measuring the variations between two consecutive frames acquired from the same (moving) camera [? ], [? ]. Even though the introduction of stereo cameras helps to measure distances using visual information, 3D sensors and laser scanners have much higher accuracy, providing distance measurements within centimetre-accuracy in the far-range [? ]. Such a precise spatial information is fundamental for the control system to calculate the steering command to be applied to the vehicle in real-case scenarios to perform obstacle avoidance [? ].

The most used sensors for ADAS features in cars are radars and ultrasonic sensors, implemented in the vehicles' bumper to detect the distance between vehicle and objects in tasks such as adaptive cruise control [? ] and automatic parking [? ], [? ]. In the adaptive cruise control, the distance to the front vehicle is measured using the front radar and used as information to brake in case the distance is shorter than a designed threshold, hence maintaining the safety distance. The ultrasonic sensors are commonly used to implement automatic parking, a set of sensors is placed on the vehicle bumper providing a set of distances in the 2D plane, the planning system is then able to compute a trajectory to park the car in specific spots while maintaining the safety distance. Such sensors are commonly referred to as "time-of-flight" sensors [? ], the principle is to emit a wave and measure the time between the emission and the moment when the wave hits back the receiver. As the speed of the wave is known, 


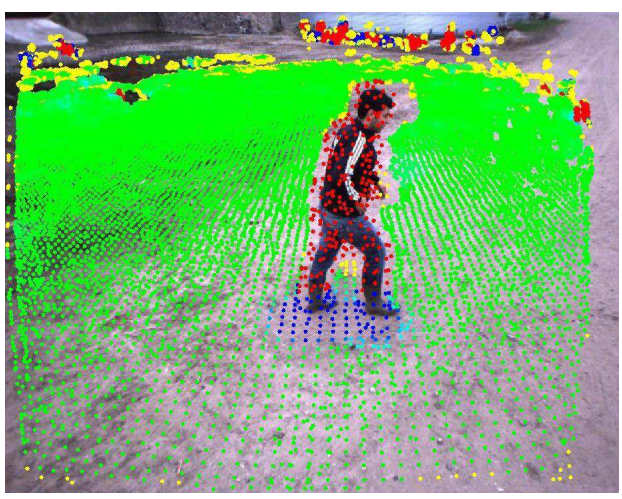

(a)

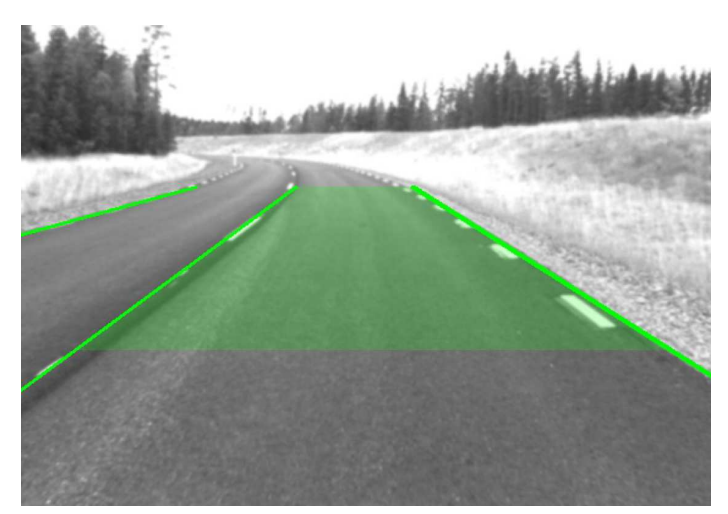

(b)
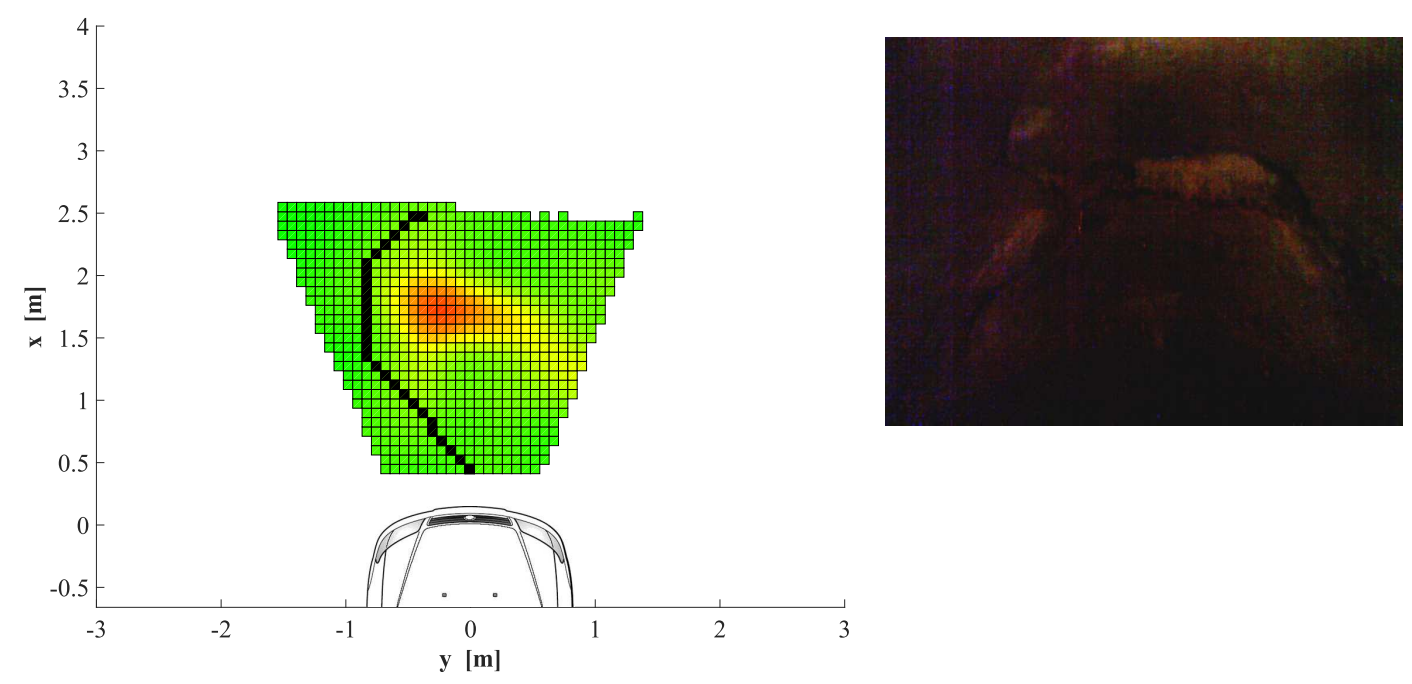

(c)

Figure 11. Examples of scene interpretation in which (a) a pedestrian is detected, (Bellone et al, 2013), in (b) the result of a lane detection algorithm is shown (Benderius et al. 2018), whereas in (c) an example camera vision mixed with depth information in low illumination conditions (Bellone et al., 2018).

the distance can be calculated easily. The ultrasonic emitters uses ultra-sound wave, whereas the radar uses radio wave. The drawback of using ultrasonic technology is that the wave also has a wide beam, which implies that the hit surface can reflect the wave in different directions, the smaller the beam the better for the reflection [? ]. However, using light waves such as in a laser or LIDARs (LIght Detection And Ranging) the beam becomes much smaller. LIDARs work with the same principles of radar and ultrasonic sensors but with the advantage of having a narrow beam providing incredibly high accuracy to distance measurements (within centimeter accuracy over 200 meter range). The main drawback of laser-based measurements for scene interpretation is the number of measurements required for the space reconstruction with the result of increasing computational burden.

Visual cameras are also fundamental for tasks such as lane/pedestrian/vehicle detection [? ], [? ], a few examples related to the recent state of the art are shown in Fig. 11. All those tasks are strongly required to be robust in future autonomous vehicles and nowadays technology already reached high accuracy in real road conditions. Benchmarks are available to measure the performances of artificial intelligence algorithms in this tasks. One of them has been realized by the Karlsruhe Institute of Technology (Germany), and the best results are continuously improved [? ]. 


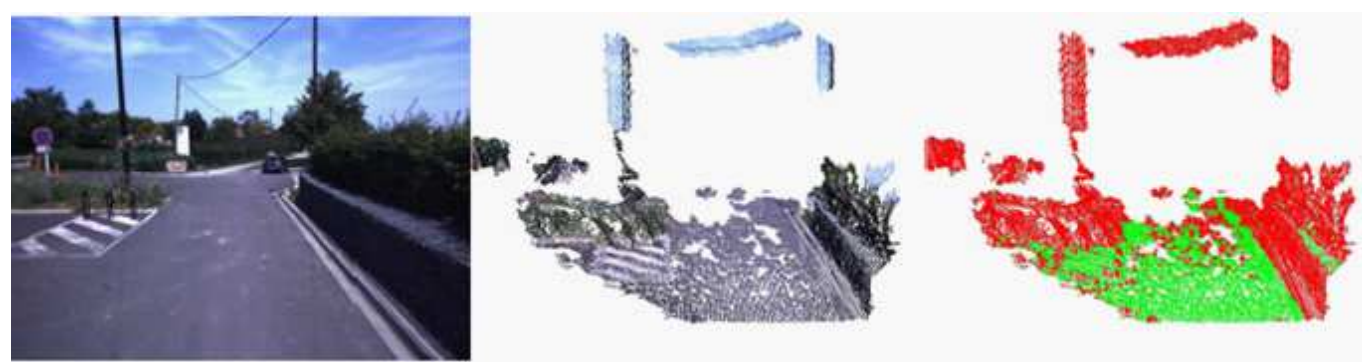

(a)

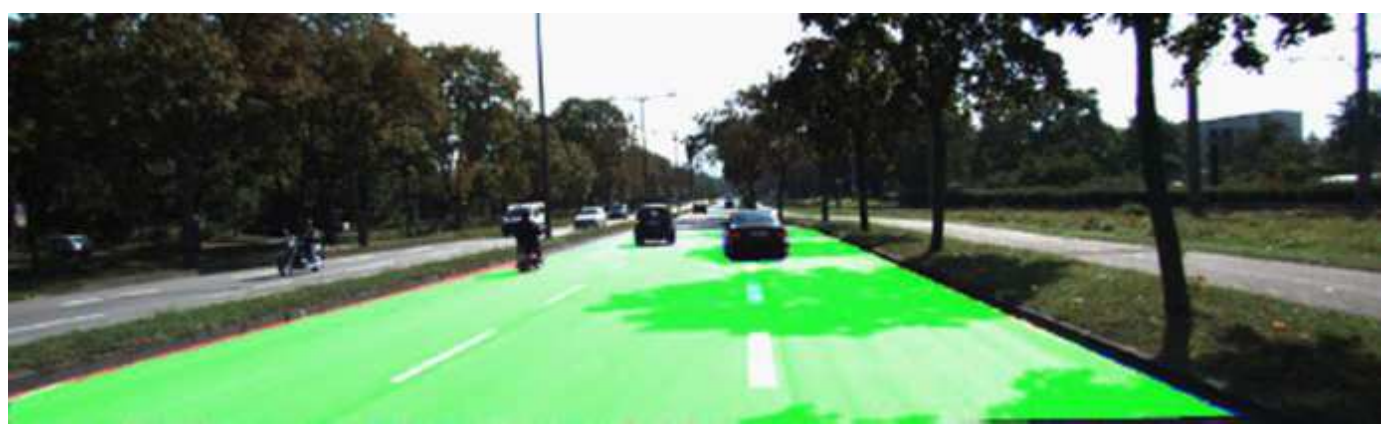

(b)

Figure 12. Road classification from 3D images using two different machine learning algorithms, (a) SVM classifier on 3D data, Source : (M. Bellone et.al 2017) and (b) deep learning approach on visual camera images enhanced with LIDAR information, Source : (Caltagirone et al., 2018).

Lane detection is already in the market, implemented in ADAS systems for keeping the vehicle in the center of the carriageway on the highway. The clear drawback is that this system does not work properly in case of not-clearly visible lane markings. Moreover, the camera being a passive sensor, it is strongly affected by lighting conditions such as high brightness or low illumination. Furthermore, they are also affected by weather conditions such as rain and snow or partially obscure lenses, while fog prevents the light reaching the sensor resulting in low contrast and blurred images [? ]. Lasers are also affected by the same weather conditions, while radars and ultrasonic sensors typically work quite well in these conditions. The difference resides in the capacity of the specific wavelength to traverse small objects.

An additional, but not trivial task, is the road classification and detection; the driverless vehicles require a deep understanding of where they are supposed to drive on the road and where they cannot. Hence, asphalt surface and side-walk have to be properly recognized. Fig. 12 reports some example of road detection using different artificial intelligence methods and different data sources, in (a) 3D data from a stereo camera are used [? ], whereas in (b) a fusion between camera images and LIDAR data was presented [? ]. In the recent state of the art, the road detection is well performed in clear and sunny conditions, the performance drops in case of nighttime and not well structured road surface. All these conditions have to be better addressed in research with the final aim of improving safety in driverless vehicles.

As discussed previously, sensors working in all conditions simply do not exist, and for this reason robotic systems, such as driverless buses, rely on the integration of sensory information coming from different sources. However, there are many situations in which the information, or only part of it, can be missing. Hence, addressing the issue of safety in autonomous driving, the minimum level of operational requirements should be defined, but these parameters are not yet determined in any technical regulation or standardization. The definition of too strict parameters can result in a high number of not-operating condition; on the other hand, too-low thresholds can lead to unsafe vehicles. 


\subsection{Infrastructure versus vehicle-based automation}

To build an effective urban transportation system, vehicles require a high-level of autonomy and intelligence. Two approaches have been studied in the literature during the last decades: infrastructure-based and vehicle-based. The first approach involves the realization of autonomous vehicles, completely reliable with the current technological level, and to modify the entire infrastructure in order to run autonomous vehicles in closed areas. This approach has been successfully used in many small-size case studies, demonstrations and few practical cases, one of them running at London's Heathrow airport ${ }^{1}$. At the airport, the entire transportation infrastructure is a completely closed area, so no other users can interfere with the vehicles. The automation is then shared between vehicles and infrastructure, both will contain sensors to improve positioning and other parameters. This approach is effective and fully working as it strongly reduces the number of possible scenarios and for this reason unexpected conditions are nearly impossible, but the costs of the implementation becomes prohibitive in populated areas and long-highways.

On the other hand, in the vehicle-based approach the infrastructure should be untouched, and the entire automation must be embedded in the vehicle. This approach has had some experimental success, though not in any road scenario. The consideration of all the possible road scenarios constitutes the main limitation to build an effective driverless vehicle that should be able to handle unexpected conditions.

An important source of variability is the weather. Currently autonomous vehicles strongly rely on sensors, of which performance degrades quickly in case of rain, fog, snow and even change in illumination.

\section{Route and vehicle specifications for robot buses}

As the current technological level of automated minibuses for public transportation is still not at the level of driving in any condition, in this section a summary of specifications and limitations will be reported including a comparison between the two most advanced products available in the market for testing [?].

The design of testing routes for robot buses has to consider the current vehicle capabilities. The following list of criteria is based on EasyMile EZ10, robot bus experiences which were used in the soon ending SOHJOA-project (2016-2018), driving on three different routes in Espoo, Helsinki and Tampere (Finland). This is the current state-of-art level, hence it provides the basic framework for route planning in the next Sohjoa Baltic demo.

\subsection{Route specifications}

1. Location: Cities are likely to see the bus operating in a popular location, where the bus may bring visibility and promote the city.

2. Real need for mobility: The robot bus can act as commuter among different modes of transportation, or for example in the internal traffic of campus areas and airports. The bus can carry one operator and eight passengers at a time on a public road (11 passengers in closed areas).

3. Requirements for the operating area: For safety reasons, the speed limit should be $30-40 \mathrm{~km} / \mathrm{h}$, so the relative velocity would not grow dangerously high between the bus and other vehicles. If the route is shared with faster vehicles, they will need to be able to overtake the robot bus safely. The best situation would be a route free of on-street parking in the area, or if it could be completely banned. If there is on-street parking, the parking area should be clearly marked and the street needs to be wide enough (see Fig. 13).

\footnotetext{
1 http://www.bbc.com/autos/story/20140910-hands-off-with-heathrows-pods
} 


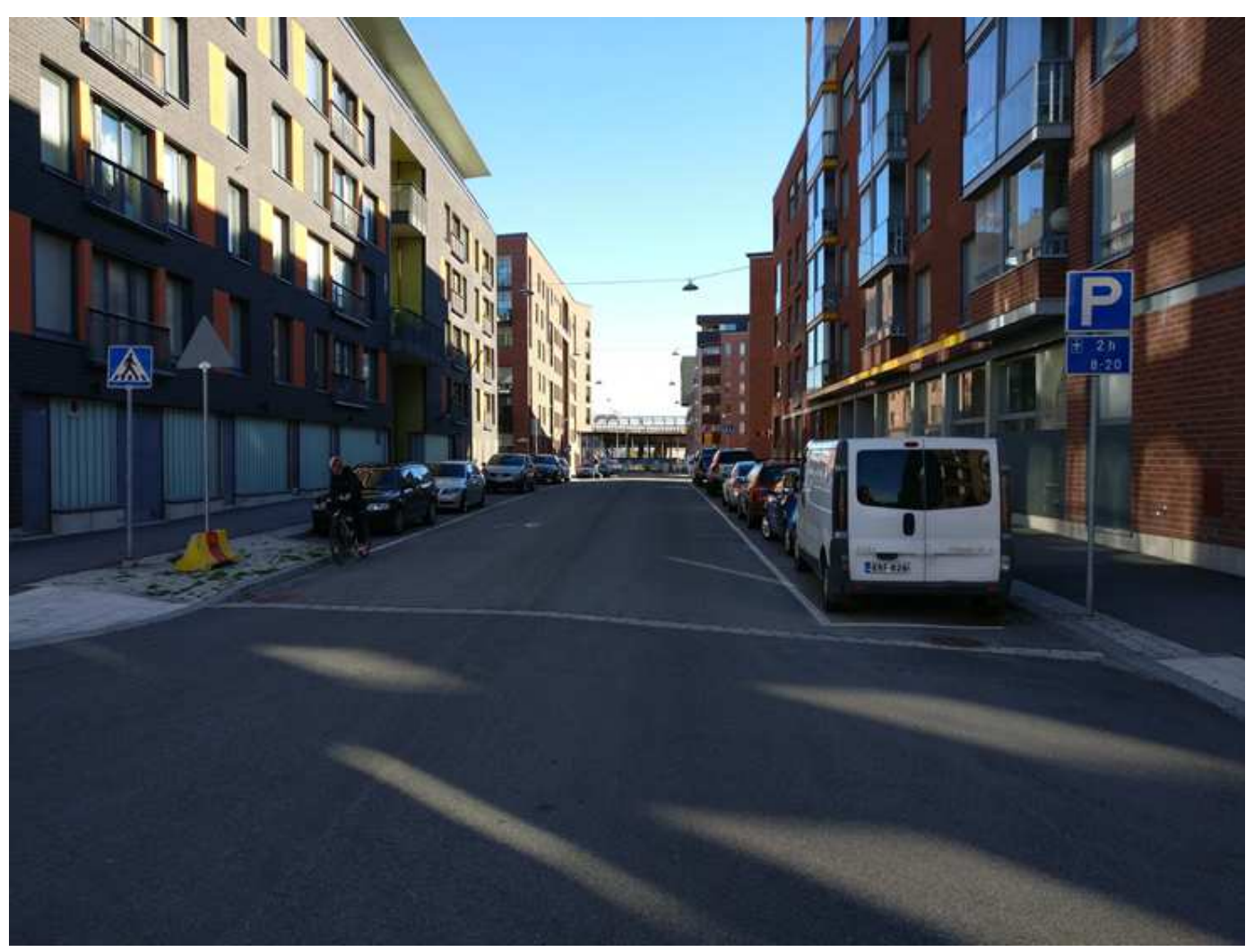

Figure 13. An example of marked street parking spaces.

The robot bus has to be able to move freely along its route. All potential distractions e.g. wrongly parked vehicles disturb the operation of the robot bus, in which case the operator has to take control over the functioning of the bus. The lane must be at least 4 meters wide, because of the required safety distance. The bus may uncomfortably slow down, if the lane is narrower. The bus should not be programmed to run closer than $1.5 \mathrm{~m}$ from identified streetside parking areas or fixed objects like roadside vegetation. The bus recognizes these things as obstacles and slows down the pace and eventually stops if an object is too close $(<0.3 \mathrm{~m})$. The robot bus needs priority in intersections. Priority was carried out by stop signs and traffic lights in SOHJOA-project. Weather conditions such as snow or heavy rain as well as the flying leaves from the trees can cause emergency stops for the robot bus as they are interpreted as an obstacle. These factors should be also noticed while planning the route.

4. Does not disturb existing public transport: For example in Helsinki, the existing mobility needs are now quite well covered by Helsinki Regional Transport (HSL) buses, trams and metros. Robot buses move considerably slower than existing motorized modes of transport so they can hinder other traffic.

5. The use of pedestrian and bicycle lanes: While planning new routes, it has been discovered that in some cases the use of light traffic lanes could create new opportunities. For example, a route from Helsinki Koivusaari metro station to Hanasaari Cultural Center, where the route would go partly on a pedestrian lane. Another example is a pilot at Helsinki-Vantaa airport, where the route was almost entirely on a pedestrian lane. The operating speed of the robot bus used in pilots is $\max 12 \mathrm{~km} / \mathrm{h}$. Because of that, the bus is more suitable among pedestrians and cyclists. However, the bus is a size of a minivan, and it takes a significant space of the lane. As a result, it may cause problems with pedestrians and cyclists. Driving the robot bus on a public road requires test plates which have to be granted by the local transportation authority, Finnish Transport Safety Agency (Trafi) for Finland. If the bus operates in a pedestrian road, the road must be marked as a yard street or as another mobility mode which allows driving also for other 
vehicles. The City of Helsinki has not granted any special permissions to the robot bus, so it is not allowed to drive on pedestrian lanes. Cities should think about using the pedestrian and bicycle lanes in terms of what is best suited for the city's own strategy. It should be noted that the use of pedestrian and bicycle traffic lanes can bring new possibilities for routes. However, the bus adjusts its speed to objects moving in front of it, this can make the bus slow down too often on the busy pedestrian lanes.

6. No traffic lights on the route: EZ10 cannot communicate with the traffic lights, so the traffic lights complicate the route increasing the necessary number of specific arrangements.

7. Storage and charging: The bus should be charged where the temperature is above zero Celsius. Charging can be carried out at normal Schuko socket and the fuse must be at least 16 A. The door to storage hall must be at least $2.5 \mathrm{~m}$ wide and $2.8 \mathrm{~m}$ high. Social facilities for the operators should be located nearby.

8. Localization of the bus: Fixed localisation points at least every 50 meters along the route (see Fig. 14).

9. Stable environment, no construction sites along the path: If the environment changes too much during the pilot, the map must be recorded again. GNSS, sufficient satellite coverage. Satellite connection is interrupted in tunnels, also tall buildings and trees next to the route may weaken or generate noise in the signal.

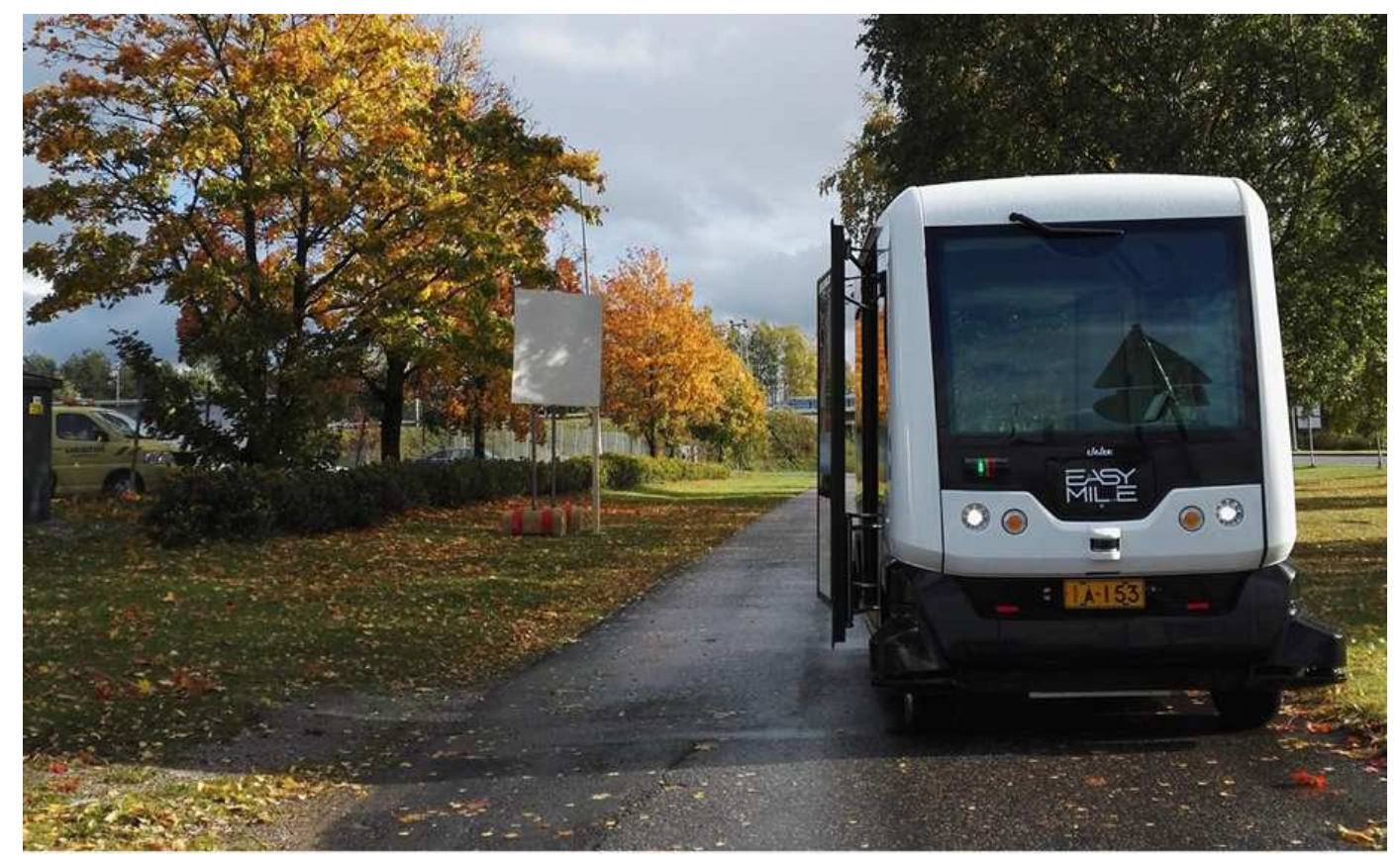

Figure 14. Localization signs were needed on the Helsinki route, there were not enough fixed structures in the end of the path.

\subsection{Vehicle specification}

Vehicle specification clearly depends on the manufacturer. Here a comparison between the most common robot buses is proposed, the Easymile EZ10 and the Navya ARMA, and reported in Table 3. They are currently considered as working prototypes, and they are not tested for nordic winter conditions. For both vehicles the deployment on the specific routes has to be performed by the manufacturer.

It should be noted that the mentioned criteria are based on a quickly evolving technology, and these versions of EZ10 robot buses were used for the first time in Finland already in 2015 at Vantaa Housing Fair. However, the characteristics of robot buses have not significantly improved in the last 
Table 3. Comparison between robot buses specifications.

\begin{tabular}{l|l|l} 
& EasyMile & Navya \\
\hline Operating temperature & $-10{ }^{\circ} \mathrm{C}$ and $40{ }^{\circ} \mathrm{C}$ & $-10{ }^{\circ} \mathrm{C}$ and $+35{ }^{\circ} \mathrm{C}$ \\
\hline Humidity & $<95 \%$ & $<95 \%$ \\
\hline Wind (continuous) & $<55 \mathrm{~km} / \mathrm{h}$ & $<55 \mathrm{~km} / \mathrm{h}$ \\
\hline Wind (temporary) & $<85 \mathrm{~km} / \mathrm{h}$ & $<85 \mathrm{~km} / \mathrm{h}$ \\
\hline Rain & $<5 \mathrm{~mm} / \mathrm{h}$ & $<5 \mathrm{~mm} / \mathrm{h}$ \\
\hline Max snow on the road & $($ light snow) $10 \mathrm{~cm}$ & $($ light snow) $10 \mathrm{~cm}$ \\
\hline Minimum friction coefficient & $>0.2$ & $>0.2$ \\
\hline Ice on the road & No ice & No ice \\
\hline Fog/steam/smoke & No & No
\end{tabular}

three years when compared to a newer model. These requirements mainly apply also to another French made robot bus, Navya ARMA.

The most important difference to be mentioned about ARMA is its ability to navigate by using only satellites, so there is no need for fixed objects along the route. However, driving with only satellite navigation requires that there are no trees, bridges or other structures on both sides or above the route that can prevent connection to the satellites (see Fig. 14).

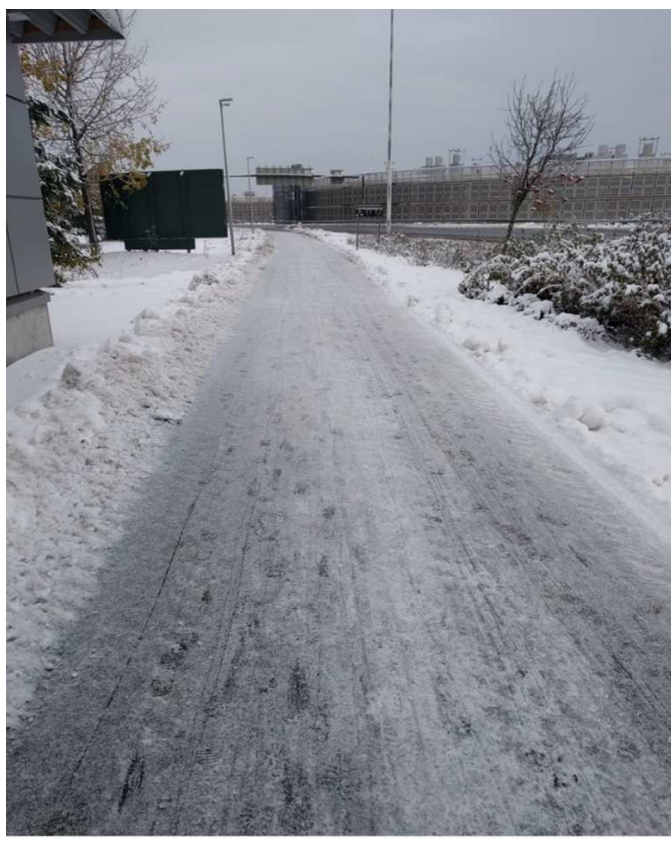

(a)

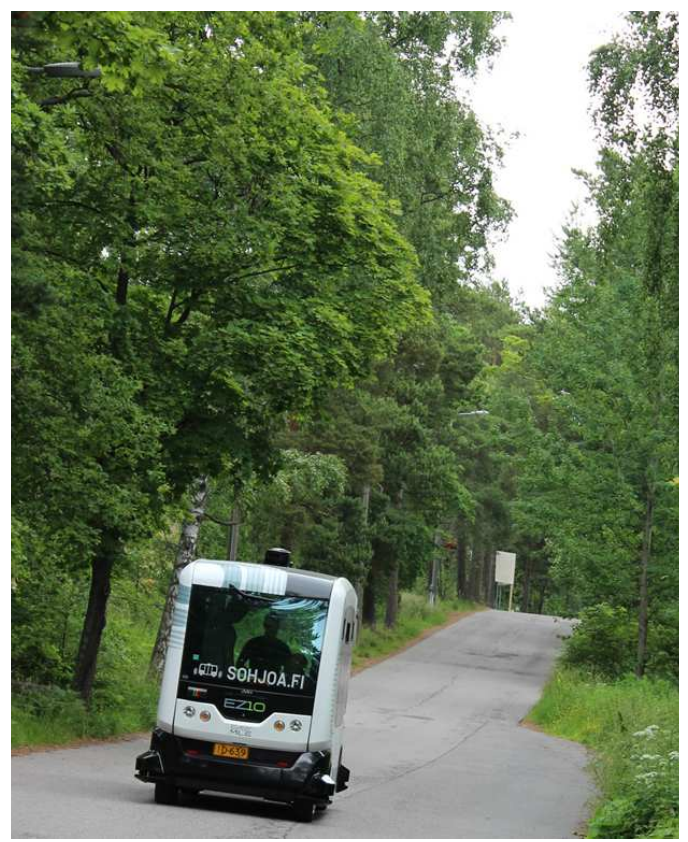

(b)

Figure 15. (a) Wintery weather stopped the operation in Helsinki pilot. The lidars of the robot bus see snow banks as obstacles. (b) An example of an area where the EZ10 robot bus localization does not work, as the trees are blocking the satellite connection and there are no fixed structures for the lidars.

But if the signal is missing, ARMA can use lidars. Navya's bus is theoretically capable of driving in $25 \mathrm{~km} / \mathrm{h}$ automatic mode and also to drive through traffic light intersections, if a communication module is installed to the traffic lights. It is also able to cope with low traffic intersections (e.g. T-junction, roundabout) autonomously by programming the traffic situation in advance. Alternatively, the bus can be determined to stop automatically just before the intersection and then the operator authorizes the bus to continue the journey by pressing a button on the screen of the bus. This feature is also present in a newer EZ10 model. 


\section{Current state of the legal framework in EU and BSR}

The development of a sound legal strategy for implementing automated bus services is a key to a successful project outcome. The following section is based on a literature review of the existing legal framework in the Baltic sea region. Here, findings regarding Germany and Sweden are summarized.

In the next stages of Sohjoa Baltic, local legal experts from other countries will help apply the results of this analysis to other legal systems.

\subsection{Germany}

A list of the relevant regulation has been compiled regarding the automated driving in Germany (see APPENDIX A).

\subsubsection{Law of vehicle approval}

Vehicles must be registered only if they are tested on public roads. Vehicle registration requires:

- An official application from the vehicle keeper.

- Motor vehicle liability insurance coverage.

- An operating license.

An automated driverless vehicle cannot receive an operating license because it does not comply with European law (e.g. UNECE rules) or international law:

- At the international level, UNECE rules require automated vehicles to be designed such that the driver may, at any time and by deliberate action, override the automated driving function (UNECE Regulation No. 79, 5.1.6).

- The Vienna Convention on Road Traffic (Art. 8) requires every moving vehicle to have a driver².

Other regulations may restrict the use of automated functions in vehicles:

- The automatic functions of the automated car must comply with regulations on the driver's behavior.

- Technical regulations requiring cars to have seat belts, a steering wheel, mechanical breaks, and automobile mirrors may present additional hurdles.

The presence of a "vehicle operator" on board may resolve some of the legal problems. Even with a vehicle operator, however, UNECE Regulation No. 79 prohibits an automated vehicle from exceeding a speed limit of $12 \mathrm{~km} / \mathrm{h}$. In addition, it is impossible to avoid violating some provisions of the German Road Traffic Regulations (StVO).

In exceptional situations, a special permit can be granted to exempt the automated car from existing regulations. Vehicles are eligible for such permits only if technical and organizational measures are adequate to guarantee the "safe and smooth flow of traffic". The issuing agency can add obligations or other stipulations to the permit to ensure that such measures are in place. Such regulations may apply to the following:

- Geographic limitations.

- Time limits.

- Provisions under which the license can be invalidated

- The onboard vehicle operator.

2 See AUTOCITS project, Report on international regulations and autonomous vehicles, available at: https://www.autocits.eu/sites/autocits/files/AUTOCITS\%20Regulation\%20study_ABSTRACT.pdf, for an overview of which countries are linked to the Vienna convention and the implications of the respective national regulations on testing procedures with autonomous vehicles. 
- Operational safety.

- Consequences of an accident.

- Transport of persons.

- Logbook or other types of documentation.

- A passenger safety briefing.

\subsubsection{Public transport law}

Passenger transportation law is regulated under the Passenger Transportation Act (PBefG) (see APPENDIX A/Germany). Automated buses require a passenger transport permit if:

- Persons are being transported.

- A fee is charged.

- Any other financial compensation is provided.

- Transport takes place on a regular basis.

There are exceptions for passenger transport on private roads and work-related transport of employees on the premises of their employer (see APPENDIX A/Germany/FrStllgV).

For a vehicle to obtain a permit, it must satisfy the criteria for one of the following categories:

- Line-based traffic is a transport that connects a pre-determined starting and end point on a regular basis and allows passengers to board and disembark at certain stops. It does not require a timetable with specific departure and arrival times or the establishment of intermediate stops.

- Occasional traffic is a transport by taxi, rental car, or rental bus. Taxi transport refers to the transportation of passengers to places of their own choice by cars that are kept ready for service at officially designated spots. Transport by rental car or bus refers to transportation in vehicles rented by passengers for this purpose. The route and destination are determined entirely by the passengers, and the rental service responds to transit requests at the corporate office or the owner's residence. The vehicle rental must include the services of a driver; taxis and rental cars cannot be driven by the passengers themselves.

If a mode of transit does not meet the criteria for one of the categories above, it may be eligible for another type of special permit:

- If a mode of transport does not fulfil all requirements for line-based or occasional traffic, authorization can be granted under the terms of the permit for the mode of transport to which it is most similar.

- For tests of new modes of transport, a special permit can be issued for a maximum period of 4 years.

- Both types of special permits are granted only if operation of the authorized vehicle is not contrary to the public interest.

\subsubsection{Law of driving licenses}

The vehicle operator is, by law, the driver of the vehicle. He or she must be in possession of a driving license. The type of driving license required depends on the vehicle weight and length as well as the number of passengers ${ }^{3}$.

In addition to the driving license, German law demands an additional license for passenger transport under certain conditions. The additional license is needed if the mode of transport also requires a passenger transportation permit. The German Driving License Regulations (FeV) specify the exceptions to this rule (for example, if the driver has a Category D1 driving license).

3 For example, a vehicle operator must be in possession of a Category D1 driving license when operating a vehicle that is 5 meters long, weighs 3.5 tons, and was designed to transport 10 passengers excluding the driver. 
The vehicle operator must remain attentive while driving and regain control of the vehicle immediately if 1) the vehicle instructs him to do so or 2) he recognizes or would have to recognize, based on obvious circumstances, that the automatic driving functions no longer operate as intended.

The vehicle operator is advised, though not legally obligated, to complete a special safety training.

\subsubsection{Criminal law}

Criminal liability in case of accidents may be ascribed to the:

- Vehicle owner or holder.

- Manufacturer and its employees.

- Provider of the necessary data infrastructure.

- Officials at the competent authority for vehicle permits.

- Vehicle operator (if a third party outside the vehicle is harmed).

Any claim would most likely allege negligent behaviour (e.g., negligent homicide, negligent physical injury) rather than intentional conduct. Most allegations would probably be linked to:

- Deficiencies in the vehicle's technology (soft- or hardware).

- Insufficient maintenance.

- Insufficient safety briefing of the vehicle operator.

\subsubsection{Data protection and privacy law}

Beginning on 25 May 2018, the General Data Protection Regulation (GDPR) will be the central EU regulation on data protection.

In legal contexts, personal data refers to information relating to an identified or identifiable natural person. Processing of personal data is lawful if, for example, the data subject has given consent to the processing, or if processing is necessary for the performance of a task carried out in the public interest. Cameras used to facilitate the safe movement of the autonomous vehicle may capture faces of individual persons, either outside or inside the vehicle. Such recordings should only store movement information that makes personal identification impossible. If software applications are used, as in the booking system, passengers must give their consent to the processing of any personal data.

\subsection{Sweden}

Tests involving automated vehicles in Sweden currently require permits in accordance with the Ordinance on autonomous vehicle tests. To get a permit, the vehicle used must be approved for driving on roads, and it is necessary to assess whether this activity is safe in terms of where, when and how the tests are to be implemented. According to the Ordinance (2017:309) on autonomous vehicle trials, permits are required for trials with vehicles that are not approved in any other way for driving on the road. To be granted a permit for automated vehicle trials the applicant must show that traffic safety will be maintained during the trial and that the trial does not impose any major disruption or inconvenience on the surroundings. There is further, recently introduced, requirement for a driver to be present inside or outside the vehicle.This Ordinance entered into force 1 July 2017 and is valid until 1 July 2022.

\subsubsection{Law of vehicle approval}

- TF does not stipulate a requirement that a person must drive the vehicle but there is an underlying assumption that there is a person directing the vehicle.

- On the international level UNECE rules require autonomous vehicles to be designed such that the driver may, at any time and by deliberate action, override the automated driving function (UNECE rules No. 79, 5.1.6)

- The Vienna Convention on Road traffic (Art. 8) foresees that every moving vehicle shall have a driver 
There are no express requirements for drivers for every road vehicle, the third Directive on Driving Licences includes an implicit requirement to have a driver. The licensing rules in the Directive on Driving Licences are in turn based on the provisions on driving licences in the Vienna Convention on Road Traffic, which also contains provisions on which vehicles require special licences.

\subsubsection{Law of driving licenses}

A vehicle can be driven only by a steward with a driving license. Which type of driving license is needed has to be determined according to the weight and length of the vehicle as well as the number of passengers. The steward is, by law, defined to be the driver of the vehicle. When e.g. driving a vehicle with a length of 8 metres and constructed for the transport of 16 passengers, excluding the driver, a D1-type driving license is needed.

\subsubsection{Data protection and privacy law}

From the 25th May 2018 on the core regulation for data protection will be the European regulation GDPR. The legal term "personal data" requires information relating to an identified or identifiable natural person. Processing of personal data is inter alia lawful if, the data subject has given consent to the processing or if the processing is necessary for the performance of a task carried out in the public interest. The same regulations regarding data protection must be applied in the entire European Union.

\section{Issues regarding civil liability in automated driving vehicles}

Automated driving carries important implications for civil liability because the driver can no longer be held accountable for accidents (at least at SAE 5). It is therefore necessary to analyse the relevant liability laws currently in place in the countries of the BSR. In this study a desk research on civil liability under German law and Swedish Product Liability law is reported.

\subsection{Germany}

Damage resulting from vehicle collisions has legal consequences. Liability for damage is imposed on the party responsible for causing it. The liable party is generally the driver, the holder, or the vehicle manufacturer.

If the driver was at fault in the accident, he or she may be held liable for the damage under $\$ 18$ StVG. Under $§ 18 \mathrm{StVG}$, the driver is liable if it would have been possible for him or her to intervene in the collision. A party is considered capable of intervention if it has a minimum level of control over the vehicle. If the vehicle operator of an automated vehicle can stop and steer the vehicle in case of an emergency, he or she satisfies the criteria for minimum control. In this case, the driver must prove that he or she is not at fault because the damage was caused by system failure. Under §63a StVG, he or she may access the automated vehicle's mandatory data storage system for this purpose. Without a vehicle operator, however, there is no driver to hold accountable. As a result, §18 StVG is not applicable.

The injured party can also claim damages from the holder of the vehicle under $\$ 7 \mathrm{StVG}$. The holder is the person who pays the bills and has the power of disposal over the vehicle, but is not necessarily the owner or the driver. Under $§ 7 \mathrm{StVG}$, the holder is held liable without personal fault. The only exception is $\S 7(2)$ StVG, which exempts the holder from liability if the damage was caused by force majeure. Technical failures of automated driving systems do not qualify as force majeure. Thus, the liability standards for automatic driving systems are not necessarily different from those for vehicles with manual operation.

The manufacturer is liable for damages if the damage results from a defective product. Manufacturer liability is regulated under the Product Liability Act (ProdHaftG). These regulations are based on European Directive 85/374/EWG, which all EU Member States are legally bound to implement. According to 4 ProdHaftG, the manufacturer is the party that produces the final product, pieces of the final product, or basic parts of the final product. The product is defective if it cannot be used correctly for its intended purpose. Liability is limited to a maximum of 85 million Euro 
under 10(1) ProdHaftG. Claims based on the ProdHaftG do not require personal fault. As a result, the manufacturer is always liable for damage caused by driverless vehicles. The injured party is not required to prove any misconduct of, or production error by, the manufacturer. This means that the introduction of automated, driverless cars will shift liability to the manufacturer.

\subsection{Sweden}

A producer may be liable for damages if the damage is based on an error of the product. The liability is regulated in PAL. PAL is based on the European directive 85/374/EWG, which all member states of the EU are legally bound to implement. According to $\S 6$ PAL the liable party is a party that either produced, manufactured, collected or brought together the product causing the damage. "Producer" is not defined in the law. The product has a safety error if it is not as safe as reasonably can be expected for its purpose. Claims based on the PAL do not require a personal fault. Consequently, in case of driverless vehicles the producer is always liable. The damaged party does not have to prove any misconduct of or production error committed by the producer.

Product liability is considered to include the software incorporated so that it becomes part of a product. Product liability is deemed to be sufficiently extensive with the current rules. The more advanced the automatic systems that are included in a product are, the more extensive this liability will become, particularly if defects in these may result in a loss of life or health.

\section{Safety and current standardization level}

"Vision zero" is a commonly used term to refer to the goal of eliminating traffic fatalities and injuries by 2050. Unfortunately, safety often receives less attention in the market compared to other issues such as competitiveness, sustainability, resource-efficiency, or, innovation, although it is specifically considered in the transport roadmap [? ]. The objective of zero road casualties is also mentioned as the ninth of ten goals of the transport roadmap. In line with this goal, the EU aims at halving road casualties by 2020 . The EU is to be a world leader in safety and security of transport in all modes of transport [?].

\subsection{Safety standards}

Vehicle and technology certification standards for safety must evolve to allow AVs' market introduction. The main current standards for safety are the IEC61508 (Functional Safety of Electrical/Electronic/ Programmable Electronic Safety-related Systems) and the ISO 26262 Road vehicles: Functional safety. ISO 26262 is the adaptation of IEC 61508 to comply with needs specific to the application sector of electrical and/or electronic (E/E) systems within road vehicles.

It is intended to be applied to safety-related systems including electronic components installed in production passenger vehicles with maximum gross mass up to $3500 \mathrm{~kg}$. In the ISO 26262 standard important concepts related to the electronic systems in vehicles such as fault tolerance and hazards are taken into account, addressing malfunctioning behaviour in safety-related systems including their interaction.

New international certifications and standards may need to be formulated to homogenize AV requirements around the world.

\subsection{Current standardization level}

In 2014, SAE International's On-Road Automated Vehicle Standards Committee, has released an information report defining key concepts related to the increasing automation of on-road vehicles. The report was later updated according to the recent developments of autonomous driving. The automation levels span from "No automation" to "Full automation" as a function of the level of action 
needed by the driver [? $]^{4}$. Full time monitoring and action correspond to no automation which includes the majority of the consumer cars today on road. The driving assistance systems, common in medium and high-level market, are able to control the acceleration/brake or the steering wheel but the driver is still required to correct actions.

According to the standard there is a specific separation between human driven vehicles and autonomous cars, going from a partial automation to the conditional automation in which the system can drive with a driver supervision (monitoring), actions are required only in highly dynamic environments. The full automation will be only reached when the system will be able to handle all the situations without the help of the driver taking decisions on possible actions.

Several technical committees are currently working in the European Union toward the standardization of transportation, the CEN TC278 - urban intelligent transportation systems ${ }^{5}$ is specifically considering the standardization of transportation in urban areas and focusing on specific aspects of data modelling in which the autonomous transportation will be integrated as a new mode of transportation.

\section{Conclusion}

In this report a review of the state of the art of automated buses has taken place, especially considering the EU-funded Interreg project Sohjoa Baltic. The report discusses how urbanization and population growth is driving towards more environmentally sound and sustainable transport solutions like autonomous electric minibuses. It gives an overview of the different automated bus pilots around the world, including pilots which are aimed at implementing automated buses in public transport. The study also discusses a technological overview about the most important concepts in autonomous driving technologies.

Furthermore, legislation issues, which are considered as very important planning the usage of autonomous vehicles in open roads were studies with particular focus on Swedish and German legislation. The report provides a framework of different laws that can help other countries to consider their need for new legislation. In the last part, a general summary of standardization linked to autonomous driving is given, underling many aspects which are still to be clarified by the different legislators.

Funding: This research was funded by Sohjoa-baltic EU-Interreg project grant number R073.

Conflicts of Interest: The authors declare no conflict of interest.

4 SAE table available at http:/ / cyberlaw.stanford.edu/blog/2013/12/sae-levels-driving-automation

5 For CEN ITS standardization refer to http:/ / www.itsstandards.eu/urban-its 


\section{Appendix A Relevant regulations}

Appendix A.1 Finland

Title (English)

Civil Code
Federal Data Protection Act

DIRECTIVE 2007/46/EC OF THE

EUROPEAN PARLIAMENT AND OF THE

COUNCIL of 5 September 2007 establishing a framework for the approval of motor vehicles and their trailers, and of systems, components and separate technical units intended for such vehicles
Regulation on the EC approval of motor vehicles and their trailers, as well as systems, components and separate technical units for such vehicles.

\begin{tabular}{l} 
Driving Licence Act \\
Vehicle Admission Ordinance \\
\hline REGULATION (EU) 2016/679 OF THE \\
EUROPEAN PARLIAMENT AND OF THE \\
COUNCIL of 27 April 2016 on the protection \\
of natural persons with regard to the \\
processing of personal data and on the free \\
movement of such data
\end{tabular}

\begin{tabular}{l|l}
\hline Finnish Constitution & Pre \\
\hline Passenger Transportation Act. & La \\
\hline Insurance Law & Lih \\
\hline Product liability law & Tud \\
\hline Criminl code
\end{tabular}

\begin{tabular}{|c|c|}
\hline Title (Finnish) & Abbreviation \\
\hline $\begin{array}{l}\text { Suomessa siviilioikeudella } \\
\text { tarkoitetaan yksityisoikeutta } \\
\text { joka jaetaan yleiseen ja } \\
\text { erityiseen yksityisoikeuteen. } \\
\text { Yleinen yksityisoikeus } \\
\text { jakaantuu henkilö-, } \\
\text { varallisuus-, perhe- ja } \\
\text { jäämistöoikeuteen }\end{array}$ & \\
\hline $\begin{array}{l}\text { Tietosuojalaki (uusi; täydentää } \\
\text { tietosuoja-asetusta) }\end{array}$ & HE 9/2018 \\
\hline $\begin{array}{l}\text { Euroopan parlamentin } \\
\text { ja neuvoston direktiivi } \\
2007 / 46 / \mathrm{EY} \text { annettu } 5 \\
\text { päivänä syyskuuta 2007, } \\
\text { puitteiden luomisesta } \\
\text { moottoriajoneuvojen ja } \\
\text { niiden perävaunujen sekä } \\
\text { tällaisiin ajoneuvoihin } \\
\text { tarkoitettujen järjestelmien, } \\
\text { osien ja erillisten teknisten } \\
\text { yksiköiden hyväksymiselle } \\
\text { (Puitedirektiivi) }\end{array}$ & $\begin{array}{l}\text { Directive } \\
2007 / 46 / E C\end{array}$ \\
\hline $\begin{array}{ll}\text { Asetus } & \text { ajoneuvojen } \\
\text { hyväksynnästä } & \end{array}$ & $2002 / 1244$ \\
\hline Ajokorttilaki & $2011 / 386$ \\
\hline- & - \\
\hline $\begin{array}{l}\text { EUROOPAN PARLAMENTIN } \\
\text { JA NEUVOSTON ASETUS } \\
\text { (EU) 2016/679, annettu } \\
27 \text { päivänä huhtikuuta } \\
2016, \quad \text { luonnollisten } \\
\text { henkilöiden suojelusta } \\
\text { henkilötietojen käsittelyssä } \\
\text { sekä näiden tietojen vapaasta } \\
\text { liikkuvuudesta ja direktiivin } \\
\text { 95/46/EY kumoamisesta } \\
\text { (yleinen tietosuoja-asetus) }\end{array}$ & GDPR \\
\hline Perustuslaki & $1999 / 731$ \\
\hline Laki liikenteen palveluista & $2017 / 320$ \\
\hline Liikennevakuutuslaki & $2016 / 460$ \\
\hline Tuotevastuulaki & $1990 / 694$ \\
\hline Rikoslaki & $1889 / 39$ \\
\hline
\end{tabular}




\begin{tabular}{l|l|l}
\hline Road Traffic Act & Tieliikennelaki & $1981 / 267$ \\
\hline Vehicles Act & Ajoneuvolaki ajoneuvojen & $2002 / 1090$ \\
\hline Road Traffic Registration Regulation & $\begin{array}{l}\text { Asetus } \\
\text { rekisteröinnistä }\end{array}$ & $\begin{array}{l}\text { Asetus ajoneuvojen käytöstä } \\
\text { tiellä }\end{array}$ \\
\hline Decree on the Use of Vehicles on the Road & Autoverolaki & $1992 / 1257$ \\
\hline Car Tax Act & Ajoneuvoverolaki & $2003 / 1481$ \\
\hline Vehicle Tax Act & - & UNECE rules \\
\hline $\begin{array}{l}\text { UNECE - UN Vehicle Regulations - 1958 } \\
\text { Agreement }\end{array}$ & - & - \\
\hline Vienna Convention on Road Traffic & - & - \\
\hline Insurance Contract Act & &
\end{tabular}

Appendix A.2 Germany

\begin{tabular}{|c|c|c|}
\hline Title (English) & Title (German) & Abbreviation \\
\hline Civil Code & Bürgerliches Gesetzbuch & BGB \\
\hline Federal Data Protection Act & Bundesdatenschutzgesetz & BDSG \\
\hline $\begin{array}{l}\text { DIRECTIVE 2007/46/EC OF THE } \\
\text { EUROPEAN PARLIAMENT AND OF THE } \\
\text { COUNCIL of } 5 \text { September } 2007 \text { establishing a } \\
\text { framework for the approval of motor vehicles } \\
\text { and their trailers, and of systems, components } \\
\text { and separate technical units intended for such } \\
\text { vehicles }\end{array}$ & - & $\begin{array}{l}\text { Directive } \\
\text { 2007/46/EC }\end{array}$ \\
\hline $\begin{array}{l}\text { Regulation on the EC approval of motor } \\
\text { vehicles and their trailers, as well as systems, } \\
\text { components and separate technical units for } \\
\text { such vehicles }\end{array}$ & $\begin{array}{l}\text { Verordnung über die } \\
\text { EG-Genehmigung } \\
\text { Kraftfahrzeuge und ihre } \\
\text { Anhänger sowie für } \\
\text { Systeme, Bauteile und } \\
\text { selbstständige technische } \\
\text { Einheiten für diese Fahrzeuge } \\
\text { (EG-Fahrzeuggenehmigungsver }\end{array}$ & ordnung) \\
\hline Driving License Regulations & \begin{tabular}{lc|} 
Verordnung & über die \\
Zulassung & von Personen \\
zum & Straßenverkehr \\
(Fahrerlaubnis-Verordnung)
\end{tabular} & $\mathrm{FeV}$ \\
\hline $\begin{array}{l}\text { Ordinance on the exemption of specific forms } \\
\text { of transport from the norms of the Passenger } \\
\text { Transportation Act }\end{array}$ & $\begin{array}{lr}\text { Verordnung über die } \\
\text { Befreiung bestimmter } \\
\text { Beförderungsfälle } \quad \text { von } \\
\text { den Vorschriften des } \\
\text { Personenbeförderungsgesetzes }\end{array}$ & FrStllgV \\
\hline Vehicle Admission Ordinance & $\begin{array}{l}\text { Verordnung über die } \\
\text { Zulassung von Fahrzeugen } \\
\text { zum Straßenverkehr }\end{array}$ & FZV \\
\hline
\end{tabular}




\begin{tabular}{l|l|l}
\hline REGULATION (EU) 2016/679 OF THE & Datenschutz-Grundverordnung & GDPR \\
$\begin{array}{l}\text { EUROPEAN PARLIAMENT AND OF THE } \\
\text { COUNCIL of 27 April 2016 on the protection } \\
\text { of natural persons with regard to the } \\
\text { processing of personal data and on the free } \\
\text { movement of such data (EU General Data } \\
\text { Protection Regulation) }\end{array}$ & & \\
\hline $\begin{array}{l}\text { Basic Law for the Federal Republic of } \\
\text { Germany (German constitution) }\end{array}$ & Grundgesetz & \\
\hline Passenger Transportation Act & Personenbeförderungsgesetz & PBefG \\
\hline Compulsory Insurance Law & Pflichtversicherungsgesetz & PflVG \\
\hline Product Liability Act & Produkthaftungsgesetz & ProdHaftG \\
\hline Criminal Code & Strafgesetzbuch & StGB \\
\hline Road Traffic Act & Straßenverkehrsgesetz & StVG \\
\hline Road Traffic Regulations & Straßenverkehrsordnung & StVO \\
\hline Road Traffic Licensing Regulation & Straßenverkehrs-Zulassungs-OrdftithzO \\
\hline $\begin{array}{l}\text { Agreement concerning the adoption of } \\
\text { uniform technical prescriptions for wheeled } \\
\text { vehicles, equipment and parts which can be } \\
\text { fitted and/or be used on wheeled vehicles } \\
\text { and the conditions for reciprocal recognition } \\
\text { of approvals granted on the basis of these } \\
\text { prescriptions (1958 Agreement) }\end{array}$ & & UN(ECE) \\
\hline $\begin{array}{l}\text { Vienna Convention on Road Traffic } \\
\text { Insurance Contract Act }\end{array}$ & Wiener Übereinkommen über \\
\hline den Straßenverkehr & - \\
\hline & Versicherungsvertragsgesetz & VVG \\
\hline & & \\
\hline
\end{tabular}

\section{Appendix A.3 Poland}

The Act on Electromobility and Alternative Fuels ("Act") was signed by the Polish president on 5th of February 2018. The Act's main focus is on the issue of electromobility, and is intended to promote electromobility and alternative fuel vehicles. However, the act also describes the procedure enabling tests of autonomous vehicles. According to the newly introduced act research works on public roads may be carried out, in particular, for the use of autonomous vehicles in collective transport and other public tasks, provided that safety requirements and authorization are met.

These safety requirements are not concretised at any given moment. The organizer of the research work can be anyone (both a natural person and an organizational unit), because the law does not specify any criteria that such an entity should meet.

The permit will be issued by the road administrator, after consultation with the inhabitants of the area. The owner of the real estate located on the route of the vehicle will be able to raise an objection, which will result in the refusal of the permit. In order to apply for a permit, it will be necessary to obtain the consent of the competent road administrator and to consult the regional police chief regarding the impact of research on the traffic flow along the planned route on which the autonomous vehicle will move.

It was not decided to introduce any tests in closed areas. The organizer's request for research work must include: information about the place and dates of research works, the route of the autonomous vehicle, as well as a list of persons responsible for securing the route.

Persons responsible for securing the route do not have to have any security qualifications because no requirements have been formulated against them. 
The duty of the organizer of research works is providing the wider public with information on planned research works and the route of the autonomous vehicle. The Act, however, does not specify the information channel and time frame to fulfil this obligation.

Within three months from the end of the tests, the organizer is obliged to provide the Director of Transport Technical Supervision with a report on the research carried out.

Appendix A.4 Sweden

\begin{tabular}{|c|c|c|}
\hline Title (English) & Title (Swedish) & Abbreviation \\
\hline $\begin{array}{l}\text { Instrument of Government (Swedish } \\
\text { constitution) }\end{array}$ & Regeringsformen & RF \\
\hline Personal Data Act & Personuppgiftslag 1998:204 & PUL \\
\hline $\begin{array}{l}\text { DIRECTIVE 2007/46/EC OF THE } \\
\text { EUROPEAN PARLIAMENT AND OF THE } \\
\text { COUNCIL of } 5 \text { September } 2007 \text { establishing a } \\
\text { framework for the approval of motor vehicles } \\
\text { and their trailers, and of systems, components } \\
\text { and separate technical units intended for such } \\
\text { vehicles }\end{array}$ & - & $\begin{array}{l}\text { Directive } \\
2007 / 46 / \mathrm{EC}\end{array}$ \\
\hline The Swedish Road Traffic Ordinance & Trafikförordning (1998:1276) & TF \\
\hline Vehicle Act* & Fordonslag (2002:574) & FordL \\
\hline Vehicle Ordinance $^{*}$ & Fordonsförordning (2009:211) & FordF \\
\hline Ordinance on autonomous vehicle trials & $\begin{array}{l}\text { Förordning (2017:309) om } \\
\text { försöksverksamhet } \\
\text { självkörande fordon }\end{array}$ & SjälvKörF \\
\hline $\begin{array}{l}\text { REGULATION (EU) 2016/679 OF THE } \\
\text { EUROPEAN PARLIAMENT AND OF THE } \\
\text { COUNCIL of } 27 \text { April } 2016 \text { on the protection } \\
\text { of natural persons with regard to the } \\
\text { processing of personal data and on the } \\
\text { free movement of such data (General Data } \\
\text { Protection Regulation) }\end{array}$ & Dataskyddsförordningen & GDPR \\
\hline The Public Transportation Act & $\begin{array}{l}\text { Lag } \quad(2010: 1065) \quad \text { om } \\
\text { kollektivtrafik }\end{array}$ & KolltrL \\
\hline Product liability law & Produktansvarslag (1992:18) & PAL \\
\hline Product safety law & $\begin{array}{l}\text { Produktsäkerhetslag } \\
(2004: 451)\end{array}$ & PSL \\
\hline Penal code & Brottsbalk (1962:700) & $\mathrm{BrB}$ \\
\hline Motor Traffic Damage Act & Trafikskadelag (1975:1410) & TSL \\
\hline Road Traffic Registration Regulation & $\begin{array}{l}\text { Lag } \quad(2001: 558) \quad \text { om } \\
\text { vägtrafikregister }\end{array}$ & VägtrRegL \\
\hline $\begin{array}{l}\text { UNECE - UN Vehicle Regulations - } 1958 \\
\text { Agreement }\end{array}$ & - & UNECE rules \\
\hline \multicolumn{3}{|l|}{ Vienna Convention on Road traffic } \\
\hline Insurance Contract Act & $\begin{array}{l}\text { Försäkringsavtalslag } \\
(2005: 104)\end{array}$ & FörsAvtL \\
\hline Road Traffic Offences Act & Trafikbrottslagen (1951:649) & TrBrL \\
\hline Driving License Act & Körkortslagen (1998:488) & KörkL \\
\hline
\end{tabular}




\begin{tabular}{l|l|l}
\hline Driving License Ordinance & Körkortsförordning (1998:980) & KörkF \\
\hline Road Traffic Definitions Act* & $\begin{array}{l}\text { Lag om } \\
\text { vägtrafikdefinitioner }\end{array}$ & VägDefL \\
\hline Road Traffic Definitions Ordinance* & $\begin{array}{l}\text { Förordningen (2001:651) om } \\
\text { vägtrafikdefinitioner }\end{array}$ & VägDefF \\
\hline Road Signs Ordinance & $\begin{array}{l}\text { Vägmärkesförordning } \\
(2007: 90)\end{array}$ & VägMärkF \\
\hline Roads Act & Väglag (1971:948) & VL \\
\hline $\begin{array}{l}\text { European Parliament and Council Directive } \\
\text { 2006/26/EC of 20 December 2006, the Third } \\
\text { Directive on Driving Licenses }\end{array}$ & - & $\begin{array}{l}\text { Directive } \\
\text { 2006/26/EC }\end{array}$ \\
\hline $\begin{array}{l}\text { Camera Surveillance Act } \\
\text { [Ordinance on electronic announcement of } \\
\text { certain road traffic regulations] }\end{array}$ & $\begin{array}{l}\text { Kameraövervakningslag } \\
(2013: 460)\end{array}$ & KamÖvL \\
\hline $\begin{array}{l}\text { [Act with special rules concerning street } \\
\text { cleaning and signage] }\end{array}$ & $(1971: 948)$ & \\
\hline [the Planning and Building Act] & $(2010: 900)$ & \\
\hline
\end{tabular}

